\title{
Activity of Descending Propriospinal Axons in the Turtle Hindlimb Enlargement during Two Forms of Fictive Scratching: Broad Tuning to Regions of the Body Surface
}

\author{
Ari Berkowitz and Paul S. G. Stein \\ Department of Biology, Washington University, St. Louis, Missouri 63130
}

\begin{abstract}
We recorded the activity of descending propriospinal axons at the caudal end of a seven-segment (D3-D9) turtle spinal cord preparation. These seven spinal segments contain sufficient neural circuitry to select and generate fictive rostral scratching or fictive pocket scratching in response to tactile stimulation in the appropriate region of the body surface. Each turtle received two spinal transections, one just caudal to the forelimb enlargement and one in the middle of the hindlimb enlargement. Descending propriospinal axons were recorded extracellularly from the hindlimb enlargement on one side of the body, while the ipsilateral or contralateral body surface was stimulated. Concurrent recordings were made from ipsilateral and contralateral hindlimb muscle nerves to monitor fictive scratch motor patterns. We found that most tactilely responsive descending propriospinal axons were excited by stimulation anywhere within the rostral scratch or pocket scratch receptive fields on at least one side of the body, and often on both sides. The activity of these neurons was usually rhythmically modulated during fictive rostral scratching and fictive pocket scratching.

Many neurons with large excitatory receptive fields generated action potentials at their highest rate during stimulation of a particular region of the body surface on one side, and generated action potentials at progressively lower rates during stimulation of sites progressively farther away. Thus, these units were broadly tuned to a region of the body surface. Some were tuned to a region of the rostral scratch receptive field and others were tuned to a region of the pocket scratch receptive field. These data suggest that selection of the appropriate form of scratching, rostral or pocket, may be mediated by populations of broadly tuned neurons rather than by highly specialized neurons.
\end{abstract}

[Key words: spinal, interneuron, scratching, tactile, fictive, turtle, selection]

It has been difficult to ascertain the roles played by individual neurons or neuronal types in the mediation of complex behaviors in mammals. As a result, several investigators have turned to the spinal control of locomotion or scratching in nonmam-

\footnotetext{
Received Oct. 4, 1993; revised Jan. 19, 1994; accepted Mar. 2, 1994.

We thank Dr. Scott Curre for many useful discussions, Dr. Julie Fiez for computer programming assistance, and Dr. Susan Koester and Edelle Field for valuable comments on the manuscript. This work was supported by NSF Grant BNS-8908144 to P.S.G.S. NIH Grant NS30786 to P.S.G.S., and an NSF predoctoral fellowship to A.B.

Correspondence should be addressed to Ari Berkowitz, Division of Biology, California Institute of Technology, Pasadena, CA 91125

Copyright (C) 1994 Society for Neuroscience $0270-6474 / 94 / 145089-16 \$ 05.00 / 0$
}

malian vertebrates as more practical systems for elucidating principles of neural organization of vertebrate behavior (see Berkinblit et al., 1989; Roberts, 1989; Stein, 1989; Grillner et al., 1991). One promising system is the spinal control of scratching in turtles (see Stein, 1989). A turtle with a spinal transection just caudal to the forelimb enlargement responds to gentle tactile stimulation of a site on the body surface caudal to the transection by repeatedly rubbing its hindlimb against that site. There are three distinct forms of scratching: rostral scratching, pocket scratching, and caudal scratching; each uses a different motor strategy to bring the hindlimb into contact with the stimulated site (Mortin et al., 1985; Robertson et al., 1985). There is a distinct receptive field for each form of scratching (Mortin et al., 1985). Thus, neural circuitry within the spinal cord must identify the site stimulated, select an appropriate form of scratching to bring the hindlimb into contact with that site, and generate the motor pattern for that scratch form (Robertson et al., 1985).

This system is convenient to study the roles of particular sets of neurons in the selection and generation of one distinct behavior out of several possible behaviors. One hypothesis is that individual spinal interneurons carry sufficient information to select an appropriate form of scratching. A neuron answering this description would be activated by stimulation anywhere within the receptive field for one scratch form and not activated at all by stimulation outside this region. Activity in such a neuron, or in a population of such neurons, would reliably trigger the generation of one form of scratching. This hypothesis is lent credence by studies in other systems demonstrating the existence of "command neurons," stimulation of which can elicit a complete behavior (see Wiersma and Ikeda, 1964; Wine and Krasne, 1972; Kupfermann and Weiss, 1978; Larimer, 1988). An alternate hypothesis is that no single spinal interneuron carries sufficiently complete and precise information to select reliably an appropriate form of scratching; thus, the precise and reliable form selection seen in motor patterns or behavior is a net effect of activity that is distributed across a population of less specialized neurons. Neurons answering this description would have large excitatory receptive fields, the borders of which would not necessarily match the borders of any scratch form receptive field. However, such neurons would be activated most strongly by stimulation within the receptive field of one scratch form. This hypothesis is supported by experiments that demonstrate the existence of populations of broadly tuned neurons that are involved in precise visuomotor behaviors in primates (Sparks et al., 1976; Georgopoulos et al., 1982, 1993; Lcc ct al., 1988; Schwartz et al., 1988). 
Immobilized spinal turtles produce fictive scratch motor patterns that are excellent replicas of the scratch motor patterns produced when the hindlimb moves (Robertson et al., 1985). When hindlimb movement occurs, the hindlimb rubs against the body surface each time the knee extends (Mortin et al., 1985). The timing of knee extension within the hip movement cycle distinguishes each form of scratching. For example, knee extension occurs during hip flexion (or protraction) in rostral scratching; knee extension occurs during hip extension (or retraction) in pocket scratching (Mortin et al., 1985). Thus, in rostral scratching, the monoarticular knee extensor muscle, FT$\mathrm{KE}$, is active during each burst of activity in a hip flexor muscle, VP-HP; in pocket scratching, FT-KE is active between the bursts of VP-HP activity (Robertson et al., 1985). Similarly, in immobilized animals, the FT-KE muscle nerve is active during the VP-HP muscle nerve bursts in fictive rostral scratching, but between the VP-HP bursts in fictive pocket scratching (Robertson et al., 1985). The essential circuitry for generation of all three forms of fictive scratching is concentrated just rostral to and in the rostral scgments of the hindlimb enlargement, in the seventh postcervical spinal segment (the dorsal 7 or D7 segment) through the D10 segment (Mortin and Stein, 1989). Sensory afferents that innervate the rostral scratch receptive field enter the spinal cord in the midbody spinal segments, D3-D6, and those that innervate the pocket scratch receptive field enter the spinal cord in the D6-D8 segments (Mortin and Stein, 1990). Thus, much of the spinal region crucial for generation of rostral scratch and pocket scratch motor patterns is located caudal to the spinal regions innervating the rostral scratch and pocket scratch receptive fields. This means that signals necessary for tactile elicitation of rostral scratching or pocket scratching must be carried by descending spinal axons. Most turtle sensory afferents terminate within the spinal segment of entry or the adjacent segments (Kusuma and ten Donkelaar, 1979, 1980a; Ruigrok, 1984), although a few have been seen to project as many as six segments caudally (Kunzle and Woodson, 1983; Ruigrok, 1984). On the other hand, there are several types of spinal interneurons with descending axons (i.e., descending propriospinal neurons) that process inputs from tactile afferents within the segment of entry (Currie and Stein, 1990). Thus, descending propriospinal neurons most likely play a major role in mediating the tactile elicitation of rostral scratching and pocket scratching. In addition, the cells of origin and funicular projections of dcscending propriospinal neurons have been described in the turtle (Kusuma and ten Donkelaar, 1980b; Berkowitz and Stein, 1992, 1994a; Berkowitz, 1993). Therefore, we have chosen to focus our investigation on descending propriospinal neurons to learn the roles played by turtle spinal interneurons in fictive scratching.

I he D3-D9 spinal segments are able to produce clearly recognizable rostral scratch or pocket scratch fictive motor patterns in response to tactile stimulation within the appropriate region in a turtle with two spinal transections, one just caudal to the forelimb enlargement and one in the middle of the hindlimb enlargement (Mortin and Stein, 1989). This paradigm offers an opportunity to study how the spinal cord selects one of two forms of fictive scratching in relative isolation from other behaviors. In such doubly transected turtles, we have studied stimulus-related and motor-related properties of descending propriospinal axons in the caudal D9 segment, using tactile stimulation to evoke fictive rostral scratching or fictive pocket scratching. General properties and stimulus-related properties of descending propriospinal neurons are described in this article. Phase analyses of descending propriospinal neurons with respect to the motor rhythms of rostral or pocket fictive scratching are described in the following companion article (Berkowitz and Stein, 1994b).

These experiments have been reported previously in abstract form (Berkowitz and Stein, 1990, 1991) and in a doctoral thesis (Berkowitz, 1993).

\section{Materials and Methods}

Surgical preparation. Adult red-eared turtles, Trachemys scripta elegans (formerly Pseudemys scripta elegans), 300-700 gm, were placed in crushed ice for at least $1 \mathrm{hr}$ prior to surgery to induce hypothermic analgesia (Melby and Altman, 1974; Marcus, 1981). Each turtle was kept partly immersed in crushed ice throughout surgery. The first surgical procedure in each case was a dorsal laminectomy just caudal to the forelimb enlargement of the spinal cord, followed by complete spinal transection midway between the D2 and D3 dorsal roots (Fig. 1). This exposed region was sealed over with dental wax. All of the remaining procedures were conducted on regions of the body caudal to this spinal transection. Four hindlimb muscle nerves on the right side, IT-KE (triceps femoris, pars iliotibialis), AM-KE (triceps femoris, pars ambiens), FT-KE (triceps femoris, pars femorotibialis), and VP-HP (puboischiofemoralis internus, pars anteroventralis), and one hindlimb muscle nerve on the left side, VP-HP, were dissected free and prepared for electroneurographic (ENG) recording (Robertson et al., 1985). IT-KE, AM-KE, and FT-KE each innervate a knee extensor muscle; FT-KE innervates the monoarticular knee extensor muscle. VP-HP innervates a hip protractor (flexor) muscle. Each muscle nerve was tied with suture near its muscle insertion and cut distal to the tie. Four segmental nerves on the right side, D4, D5, D6, and D7, were also dissected free and prepared for en passant ENG recording (Mortin and Stein, 1990). D4-D6 innervate approximately the caudal two-thirds of the rostral scratch receptive field. D6-D7 innervate approximately the rostral two-thirds of the pocket scratch receptive field; these nerves also innervate the caudal respiratory muscles. Finally, a dorsal laminectomy was performed to expose the D7-S1 (first sacral) spinal segments. The spinal cord was completely transected between the D9 and DI0 dorsal roots, with one cut, using fine iridectomy scissors. This cut was made at approximately a $45^{\circ}$ angle from dorsorostral to ventrocaudal, so that the cut face at the caudal end of the D9 segment was visible from the dorsal surface of the animal.

The turtle was allowed to warm up to room temperature and injected intramuscularly with the neuromuscular blocker gallamine triethiodide (Flaxedil) at a dose of $8 \mathrm{mg} / \mathrm{kg}$. On both sides of the turtle, the shield borders, skin borders, and pigmentation markings were traced onto clear contact paper placed against the turtle's side, for later receptive field mapping (Currie and Stein, 1990). Warm dental wax was molded into wells to surround each of the surgically exposed regions, one each for the exposed nerves on each side and a third for the exposed D7-S1 spinal cord. Wells were glued to the turtle's shell using Permabond 910 adhesive. The nerve wells were filled with mineral oil and the spinal cord well was filled with turtle saline. The trachea was intubated and the turtle maintained on artificial respiration at room temperature for the remainder of the experiment.

Recordings. Recordings were obtained from each nerve using a pair of 0.004 inch silver wire hook electrodes (Robertson et al., 1985). Single descending propriospinal axons were recorded from the cut face of the spinal cord, in the white matter on the right side of the caudal D9 segment, using a glass microsuction electrode with an inner diameter of $2-4 \mu \mathrm{m}$ (Currie and Stein, 1990). Microsuction electrodes were fabricated using a Brown-Flaming micropipette puller. The electrode was placed in a Plexiglas electrode holder with a suction port. The electrode and electrode holder were filled with turtle saline. The suction port was connected via polyethylene tubing to a $50 \mathrm{ml}$ syringe. To obtain an extracellular recording of a descending propriospinal axon, the microsuction electrode tip was placed against the caudal D9 white matter, covered with turtle saline. By moving the syringe plunger, positive pressure was applied to the white matter to separate the cut ends of axons; then, negative pressure was applied to obtain an axon recording. The white matter location of each recorded axon was marked on a camera lucida drawing of the cut spinal face. Axons were recorded throughout the dorsal funiculus and the dorsal two-thirds of the lateral funiculus. Recordings were rarely made in the ventral funiculus or the ventral third 


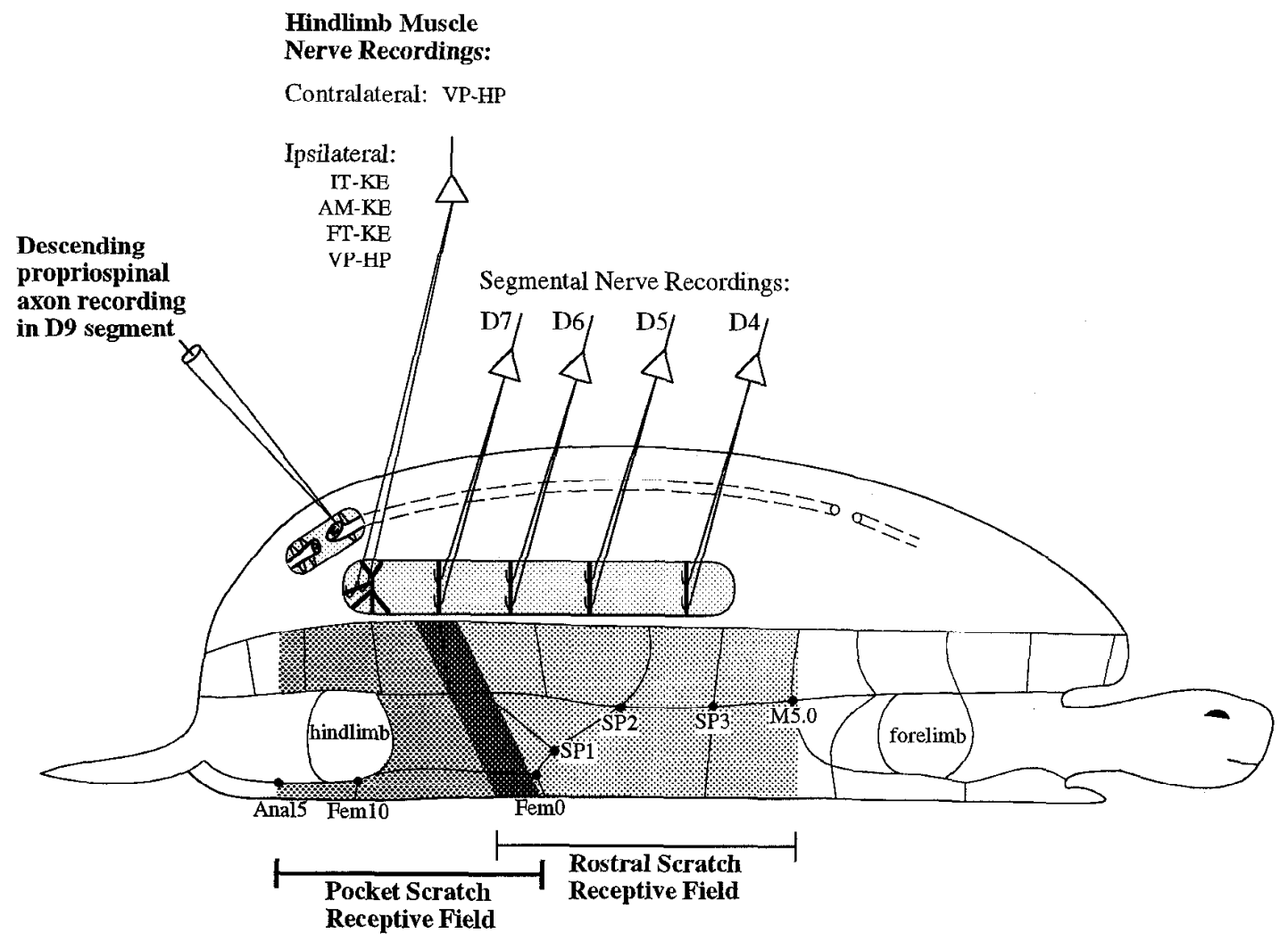

Figure 1. Illustration of the preparation with two spinal transections used to record from descending propriospinal axons in the turtle hindlimb enlargement, while also recording from segmental nerves and knee extensor muscle nerves ipsilaterally, as well as from the hip protractor muscle nerve on each side. See Materials and Methods for description of procedures. Fem, femoral plate; SPI-SP3, stimulus positions 1-3, respectively; $M$, marginal plate.

of the lateral funiculus, due to the difficulty of seeing and reaching those regions with a dorsal approach. In addition, the electrode was not placed in the vicinity of the ventral root exit zone, to avoid recording from motoneurons or sympathetic preganglionic neurons. Suction electrode recordings were passed through a high-impedance head stage. Singleunit, nerve, and stimulus recordings were amplified (bandpass, $100 \mathrm{~Hz}$ to $1 \mathrm{kHz}$ ) and stored with an 8-channel FM tape recorder (bandpass, DC to $1.25 \mathrm{kHz}$ ). Single units were isolated with an analog delay and a two-point window discriminator (BAK Electronics), which in turn was used to trigger an interspike interval converter (BAK Electronics). Records were printed using an 8-channel thermal-array chart recorder (Astro-Med; bandpass, DC to $5 \mathrm{kHz}$ ).

Stimulation. Single-unit excitatory receptive fields were mapped using a fire-polished glass probe, delivering up to about $1.2 \mathrm{~N}$ of force $(120$ $g$ force). If a unit increased its firing rate during stimulation of a particular site on most trials, this site was considered part of the unit's excitatory receptive field. This definition of receptive field included monosynaptic as well as polysynaptic inputs to the unit from tactile primary afferents; polysynaptic inputs to the unit could include those from central pattern-generating neurons activated by the tactile stimulus. Whenever a unit's receptive field is illustrated (see $B$ in Figs. 27), the entire region that was tested and that evoked an excitatory unit response is marked with stippling (or stippling and solid areas; see Figs. $2,7)$. If sites just outside a given region of stippling were stimulated without evoking an excitatory unit response, a dark line surrounding this stippled region is used to indicate that this was an excitatory receptive field border. If sites just outside a given region of stippling were not stimulated, no dark line is included, indicating that the unit's excitatory receptive field may have continued farther in this locale. The borders of the regions in which scratch motor responses could be evoked are indicated by thick vertical bars. In most cases, the unit's excitatory receptive field was mapped on both sides of the body. In some cases, unit excitatory receptive fields were also mapped using a series of calibrated von Frey hairs, delivering from $0.06 \mathrm{mN}$ to more than $1 \mathrm{~N}$. The glass probe or von Frey hair was attached to a hand-held force transducer (Grass Instruments). The shell or skin was sometimes stimulated clcctrically, via two closely spaced pins, using $1-20 \mathrm{~V}$ pulses of $1 \mathrm{msec}$ duration (Currie and Stein, 1990). For units with spontaneous activity, inhibitory receptive fields were sometimes mapped using mechanical stimulation alone. For units with no spontaneous activity, inhibitory sites were sometimes found using two-site stimulation: the unit response to stimulation at an excitatory site could be reduced while an inhibitory site was also stimulated. Segmental nerves (D4-D7) were sometimes stimulated via the recording electrodes, using $0.2-10 \mathrm{~V}$ pulses of $50 \mu \mathrm{sec}$ duration. High-frequency nerve stimulation (up to 100 $\mathrm{Hz}$ ) was used to distinguish propriospinal neurons from primary afferents; units that showed latency jitter were considered to be propriospinal (Curric and Stcin, 1990). At the start of each experiment, the ipsilateral rostral scratch and pocket scratch receptive fields were mapped by stimulating the body surface with a glass probe while observing motor responses in ipsilateral FT-KE and VP-HP. At the end of each experiment, the D4-D7 segmental nerves were cut centrally and the D4-D7 dermatomes were each mapped by listening to the amplified segmental nerve recording via an audio monitor while stimulating the body surface with a glass probe. Sites on the body surface that were used for stimulation have been described previously (Mortin et al., 1985; Mortin and Stein, 1990; see Fig. 1 for locations of some stimulation sites).

Unit classification. Isolated single propriospinal neurons were included in this study if and only if they showed a clear response to mechanical stimulation of some location(s) within the rostral scratch receptive field or pocket scratch receptive field and had been tested for at least one site in each of these receptive fields on at least one side of the body. Unit excitatory receptive fields were classified as unisegmental or multisegmental by noting unit response or lack of response to stimulation of each of the D4-D7 nerves, and by comparing unit tactile receptive fields to the D4-D7 dermatomes mapped in the same animal and previously published average dermatomes for other spinal segments.

Whenever sufficient data were available, a quantitative determination was made of whether the unit's activity was rhythmically modulated during fictive scratching. This was done by applying the Rayleigh test 
at the $p<0.01$ level to dual-referent phase histograms with respect to the activity cycle of the VP-IIP nerve on the side stimulated (see Materials and Methods of following companion article, Berkowitz and Stein, 1994b). In some turtles, the VP-HP burst onsets and offsets were not sufficiently clear to apply quantitative methods. In addition, some units were not active with high enough firing rates for a reliable quantitative evaluation of rhythmic modulation. For each site stimulated, the Rayleigh test was used only if at least two full cycles of nerve activity and at least 10 unit action potentials (spikes) occurred during the stimulation (see Berkowitz and Stein, 1994b). For most of the units for which the quantitative test could not be applied, the data were sufficiently clear to allow a qualitative assessment of whether or not the unit's activity was rhythmically modulated during fictive scratching.

Firing rate calculation. In order to quantify single-unit firing rates during fictive scratching for each location stimulated, both the unit recording and the ENG recording of the VP-HP nerve on the same side as the stimulation were digitized at $2 \mathrm{kHz}$, full-wave rectified, and integrated in $10 \mathrm{msec}$ bins. The number of unit spikes per second was then calculated for each VP-HP activity cycle (from one VP-HP burst onset to the next VP-HP burst onset). Fictive scratch motor patterns recorded differed in duration of the stimulation episode and in frequency of naturally occurring variations, such as HR-KF deletions (Robertson and Stein, 1988; previously termed "B phase deletions" by Stein and Grossman, 1980). To provide comparable and standard data sets, cycles were included in this analysis only if they involved a single clear VPHP burst and a single clear VP-HP quiescent period. The first cycle in each stimulation episode was omitted, as this cycle was often very different from the rest. No cycles that began after the end of stimulation were included. The first $10 \mathrm{sec}$ of such cycles from each stimulation episode were used; cycles that began later were omitted from this analysis, as fictive scratching and unit activity often become gradually weaker late in the stimulation episode. For each site of stimulation, unit firing rates were averaged for all cycles of this standard data set, to obtain a mean value of spikes per second and the SEM. All available stimulation episodes were included from stimulation sites along the epidermal shield borders from anal 5 to femoral 0 and from SP1 to marginal 5.0 on both sides of the body (see Mortin et al., 1985; Mortin and Stein, 1990; and Fig. 1 for descriptions of sites). The sites from anal 5 to femoral 0 are located on the shell near the junction of the skin and the shell. This type of analysis was performed for all units that showed excitatory responses to mechanical stimulation of four or more such sites on one side of the body.

\section{Results}

Recordings were made from 104 descending propriospinal axons in 18 animals. Units were classified primarily according to whether their excitatory receptive fields included the dermatome of only one spinal segment, several spinal segments, or the entire regions of the rostral scratch receptive field and pocket scratch receptive field. Units were secondarily classified according to whether their activity was rhythmically modulated during rostral or pocket fictive scratching (see Materials and Methods for classification procedures). For 55 units, sufficient data were available to assess quantitatively their rhythmic modulation during fictive scratching, using the Rayleigh test (see Materials and Methods in Berkowitz and Stein, 1994b).

Units that had larger excitatory receptive fields were more likely to have rhythmically modulated activity during fictive scratching. Eight units $(8 \%)$ had a unisegmental excitatory receptive field (unisegmental RF units). For two of these units, sufficient data were available to perform the Rayleigh test. Neither of these two unisegmental RF units was rhythmically modulated during fictive scratching. Thirty-four units $(33 \%)$ had a multisegmental excitatory receptive field that did not include all of the rostral scratch and pocket scratch receptive fields on one side (multisegmental RF units). Sufficient data were available to perform the Rayleigh test for 15 of these units. Eleven $(73 \%)$ of these 15 multisegmental RF units were rhythmically modulated during fictive scratching. Fifty-eight units (56\%) were excited by stimulation anywhere within the rostral scratch or pocket scratch receptive fields on at least one side of the body. Thus, the majority of units recorded was excited by stimulation throughout the rostral scratch and pocket scratch receptive fields, a region innervated by six spinal segments. The receptive field of each of these units was the same as the receptive field of the fictive scratch motor response; hence, these units are termed motor RF units. For 38 motor RF units, sufficient data were available to perform the Rayleigh test. Thirty-three $(87 \%)$ of these 38 units were rhythmically modulated during fictive scratching.

In addition, four spontaneously active units were inhibited by stimulation anywhere within the rostral scratch or pocket scratch receptive fields on at least one side of the body, and did not show excitatory responses to any stimulation in rostral scratch or pocket scratch receptive fields (inhibited-only units). None of these units was sufficiently active during fictive scratching for the Rayleigh test to be performed. Nevertheless, three of these four units appeared to be rhythmically inhibited during fictivc scratching.

Six units (one unisegmental RF unit, four multisegmental RF units, and one motor RF unit) displayed sufficiently rapid adaptation to stimulation that they were not active during the motor pattern. Therefore, these six neurons did not show rhythmic modulation during fictive scratching.

For an additional 32 units, sufficient data were available to make a qualitative, but not quantitative, assessment of whether or not they were rhythmically modulated during fictive scratching. None of five unisegmental RF units, seven $(70 \%)$ of 10 multisegmental RF units, and $11(65 \%)$ of 17 motor RF units appeared to be rhythmically modulated. For the remaining seven units (one unisegmental RF unit, four multisegmental RF units, and two motor RF units), either the motor patterns were insufficiently rhythmic or the unit was insufficiently active to make a qualitative assessment of whether or not they were rhythmically modulated during fictive scratching (see Materials and Methods).

Each side of the body was stimulated during recordings from 67 units; of these units, there were 6 unisegmental RF units, 15 multisegmental RF units, 43 motor RF units, and 3 inhibitedonly units. Units with larger receptive fields were more likely to show excitatory responses to stimulation contralateral to the recorded axon. All of the unisegmental RF units were excited only by ipsilateral stimulation; in one such case, it was demonstrated that contralateral stimulation inhibited the unit. Eleven $(73 \%)$ of the multisegmental RF units were excited only ipsilaterally; in two such cases, it was demonstrated that contralateral stimulation inhibited the unit. Three multisegmental RF units $(20 \%)$ were excited by stimulation of either side and one $(7 \%)$ was excited only by contralateral stimulation. Of the motor RF units, just seven (16\%) were excited only by ipsilateral stimulation; for three of these, inhibition by contralateral stimulation was demonstrated. Thirty-four (79\%) of the motor RF units were excited by stimulation of either side, while two $(5 \%)$ were excited only by contralateral stimulation; for one of the latter, inhibition by ipsilateral stimulation was demonstrated. Of the 34 motor RF units with bilateral excitatory receptive ficlds, $22(65 \%)$ gencrated spikes at a higher rate during ipsilateral stimulation, seven ( $21 \%)$ fired at a higher rate for contralateral stimulation, and five $(15 \%)$ fired at about the same rate during stimulation of the two sides. The three inhibited-only 

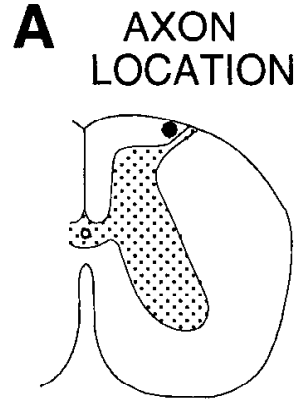

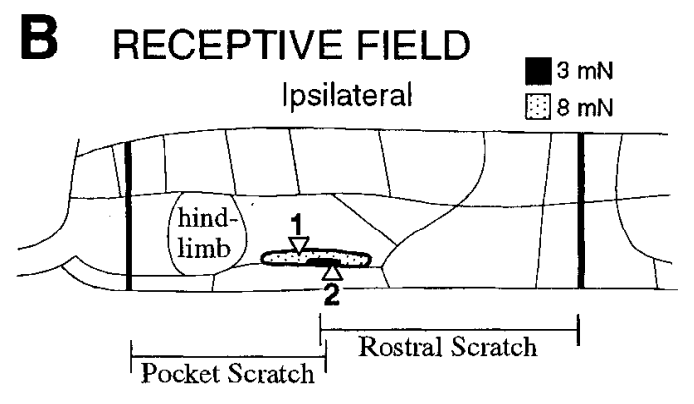

C ELEC. STIM. OF NERVE
INNERVATING RECEPTIVE FIELD - $50 \mathrm{~Hz}$

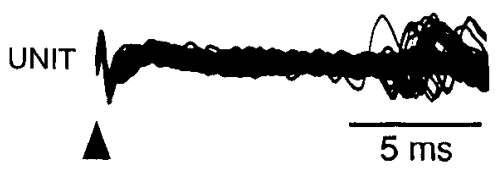

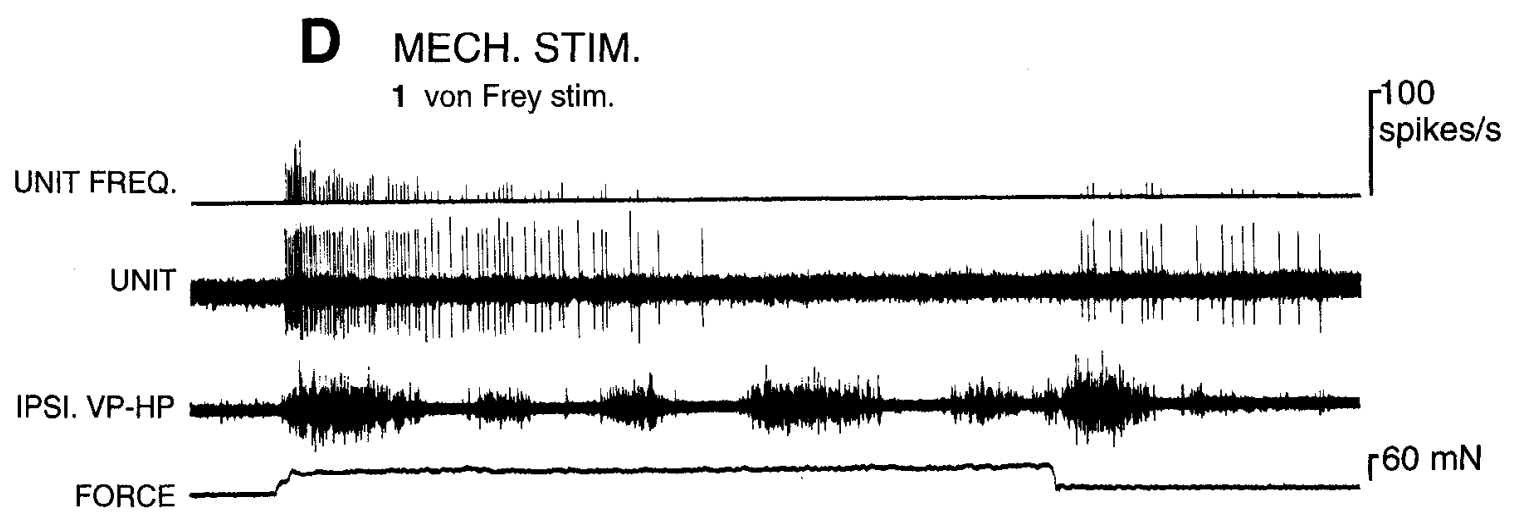

2 Glass probe stim.

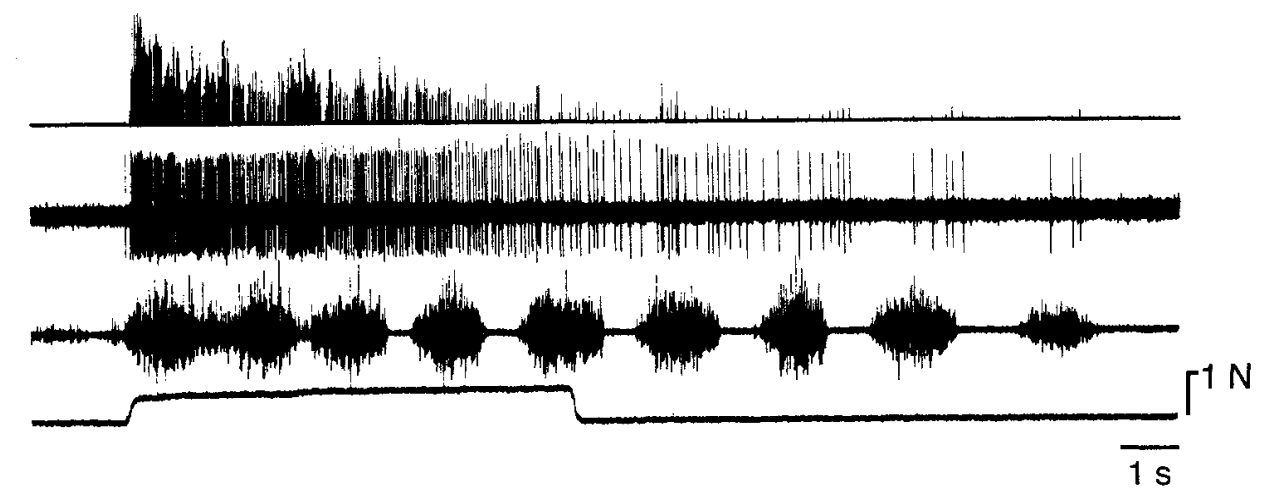

Figure 2. Example of a unisegmental RF unit. A, Axon recording location shown on a sketch of a cross section of the caudal D9 spinal cord. $\bullet$, recording location. $B$, Unit excitatory receptive field, traced on a standard drawing of the turtle's right side. The unit receptive field was mapped with calibrated von Frey hairs; the solid region and the stippled region represent subregions with different force thresholds. The dark border surrounding these regions indicates the unit's excitatory receptive field borders. Triangles labeled 1 and 2 , respectively, mark the sites stimulated in $D I$ and $D 2$, respectively. The unit's excitatory receptive field was ipsilateral to the location of the recorded axon. Thin lines on the turtle drawing represent borders of epidermal shields and of skin. Thick vertical bars indicate the rostral and caudal borders of the region of motor responsiveness in the D3-D9 turtle from which this unit was recorded. Brackets under the drawing indicate the borders of the rostral scratch and pocket scratch receptive fields in this animal. $C$, Unit response to high-frequency electrical stimulation of the right D7 nerve, which innervated the unit's excitatory receptive field. Stimuli of $1.5 \mathrm{~V}, 50 \mu \mathrm{sec}$ were delivered at $50 \mathrm{~Hz}$. Supcrimposed traces from 50 stimuli are shown. $\Delta$, stimulus artifact. $D$, Unit and ipsilateral hip protractor muscle nerve (IPSI.VP-HP) responses to mechanical stimulation in the unit's excitatory receptive field, at the sites indicated in $B$. The top trace (UNIT FREQ.) in each case is the instantaneous firing rate of the unit, the output of an interspike interval converter triggered by each unit spike. The bottom trace (FORCE) in each case is the output of a force transducer attached to the stimulating von Frey hair or glass probe. 1, Stimulation with a von Frey hair delivering $60 \mathrm{mN}(6 \mathrm{~g}$ force) in the $8 \mathrm{mN}$ region. 2, Stimulation with a glass probe in the 3 $\mathrm{mN}$ region. ELEC. STIM., electrical stimulation; MECH. STIM., mechanical stimulation.

units tested were all inhibited by stimulation of either side of the body.

\section{Examples of unit types}

Several examples of unit responses are shown below. These examples illustrate the variety of response types seen and provide detailed information on which to base hypotheses about roles that descending propriospinal neurons may play in selection and generation of scratching. However, the sample of recorded neurons did not divide up neatly into discrete types. Instead, there was a continuum in response latencies, rates of adaptation to a constant stimulus, excitatory receptive field sizes, strengths of rhythmic modulation during fictive scratching (see Berkowitz and Stein 1994b), and durations of afterdischarge. 


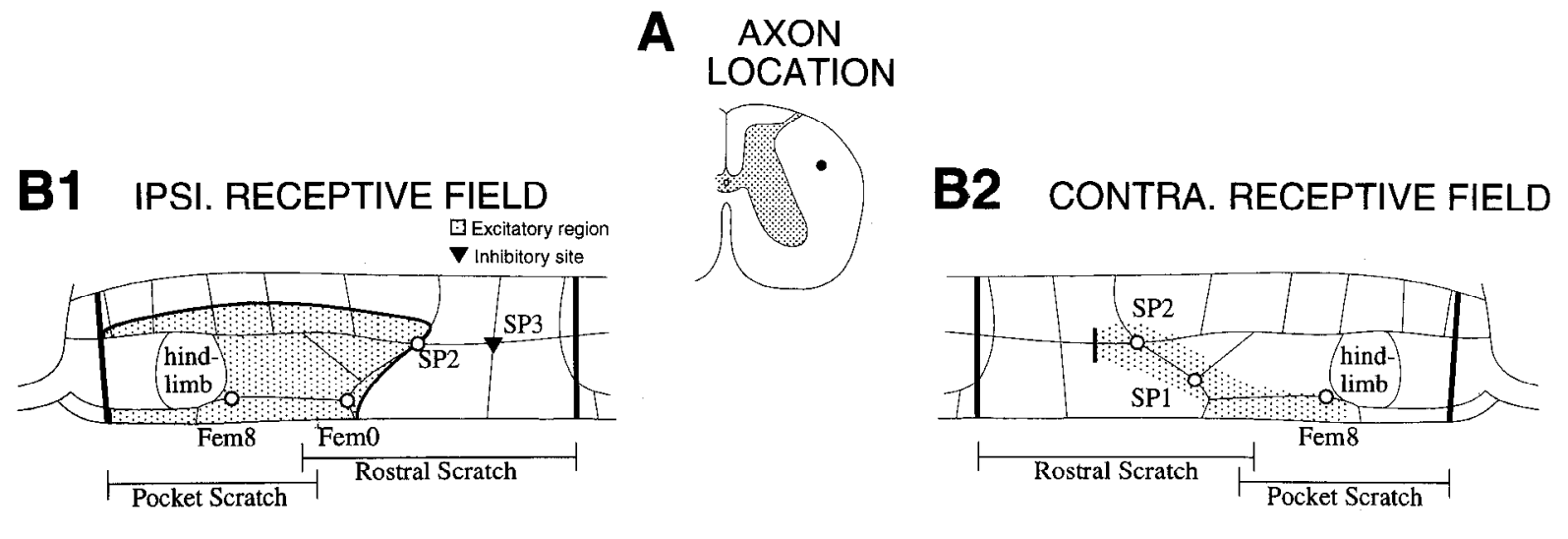

C IPSI. ANT. ROSTRAL SCRATCH

\section{F CONTRA. ANT. ROSTRAL SCRATCH}
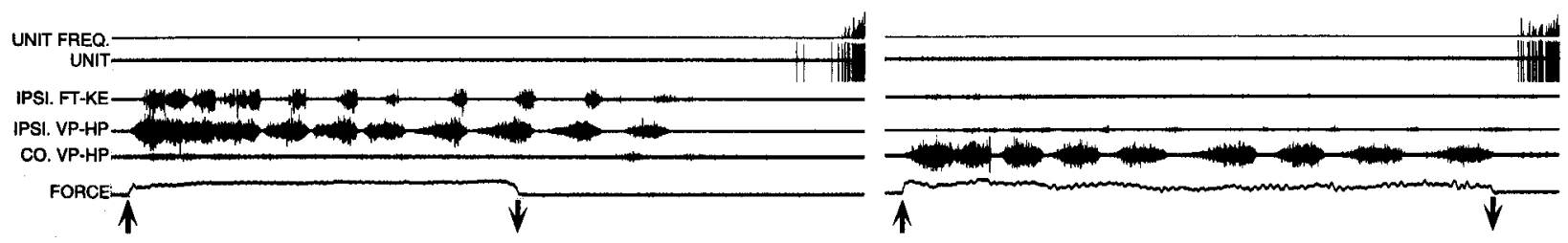

\section{IPSI. POST. ROSTRAL SCRATCH}

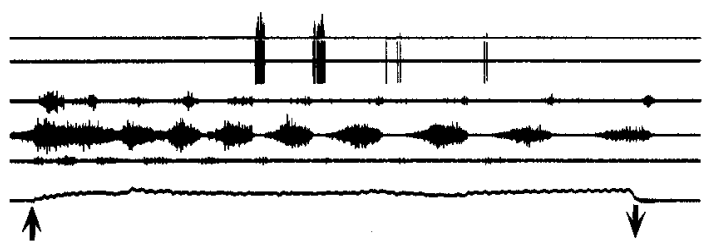

G CONTRA. POST. ROSTRAL SCRATCH

E IPSI. POCKET SCRATCH

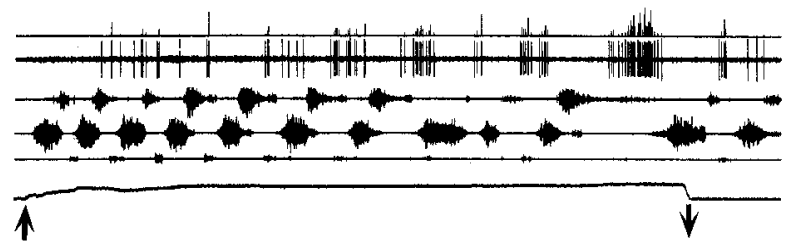

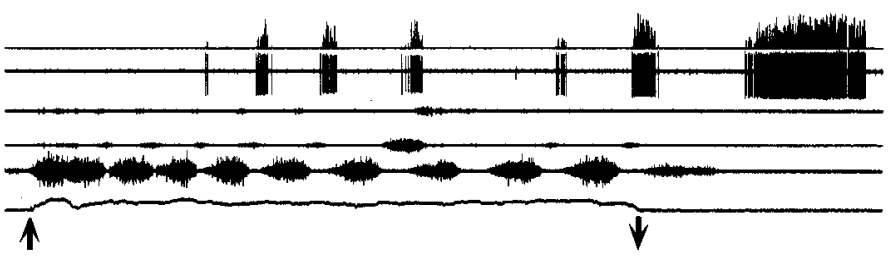

H CONTRA. POCKET SCRATCH

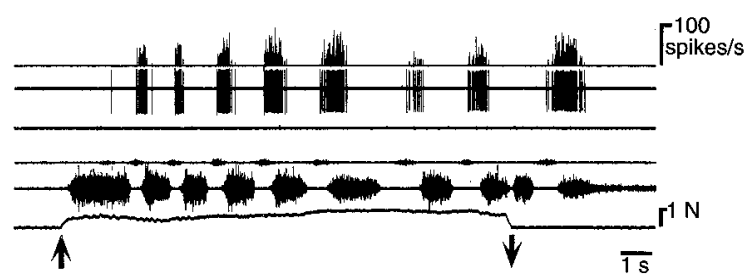

Figure 3. Example of a multisegmental RF unit with rhythmic activity during fictive scratching. $A$, Axon recording location. $B 1$ and $B 2$, Ipsilateral and contralateral unit receptive fields, respectively. Stippling marks unit's excitatory receptive field ipsilaterally and contralaterally; the dark borders that partially surround the stippled regions indicate the known borders of the unit's excitatory receptive field (see Materials and Methods). $O$, stimulation sites for which unit responses are illustrated in $\mathrm{C}-\mathrm{H} ; \mathbf{\nabla}$, an inhibitory site, for which the unit response is illustrated in Figure 8 . See Mortin et al. (1985), Mortin and Stein (1990), and Figure 1 for description of sites. C-H, Unit, ipsilateral knee extensor (IPSI. FT-KE), ipsilateral hip protractor (IPSI. VP-HP), and contralateral hip protractor $(C O$. $V P-H P)$ muscle nerve responses to glass rod mechanical stimulation at the following sites: $C$, ipsilateral SP2; $D$, ipsilateral femoral $0 ; E$, ipsilateral femoral $8 ; F$, contralateral SP2; $G$, contralateral SP1; $H$, contralateral femoral 8. Stimulation of ipsilateral SP2 $(C)$ and contralateral SP2 $(F)$ usually evoked a few unit spikes during the stimulation, but not in the cases illustrated. Up arrows indicate stimulus onset; down arrows indicate stimulus offset. $A N T$., anterior (rostral); POST., posterior (caudal). Other conventions are as in Figure 2.

The examples shown here were selected to illustrate the breadth of the spectrum for each response property.

Unisegmental receptive field unit. An example of a unisegmental RF unit is shown in Figure 2. Its excitatory receptive field (Fig. $2 B$ ) was very small, but included parts of both the rostral scratch and pocket scratch receptive fields in this animal. A comparison to the dermatome map in this animal (data not shown) indicates that the caudal border of the unit's excitatory receptive field was well within the $\mathrm{D} 7$ dermatome. The rostral border of the unit's excitatory receptive field was within a region innervated by both the D7 and the D6 nerves. However, the unit was excited by stimulation of the ipsilateral D7 nerve at a latency of 10.5-14 msec (Fig. $2 C$ ) and was not excited at all by stimulation of the ipsilateral D6 nerve (data not shown). This unit was classified as a propriospinal neuron, rather than a primary afferent, because it showed latency jitter in response to high-frequency D7 nerve stimulation (Fig. 2C). During constant-force stimulation, this unit adapted only very gradually 


\section{B1 IPSI. RECEPTIVE FIELD}

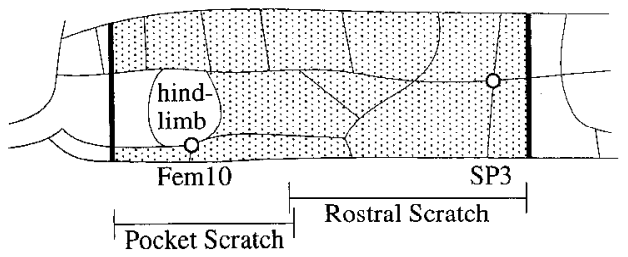

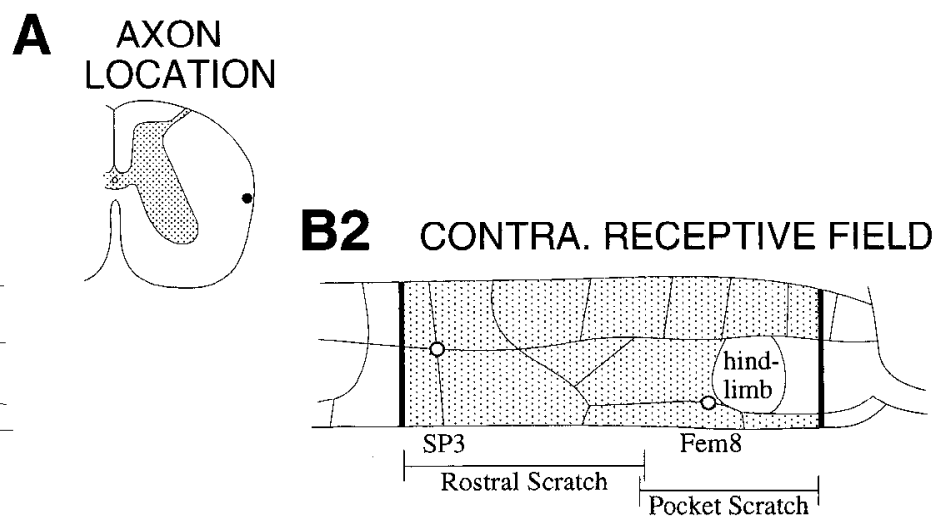

E CONTRA. ROSTRAL SCRATCH

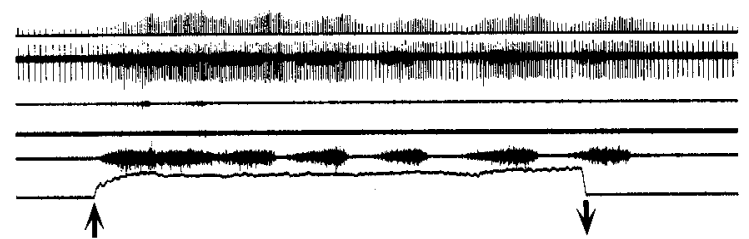

F CONTRA. POCKET SCRATCH

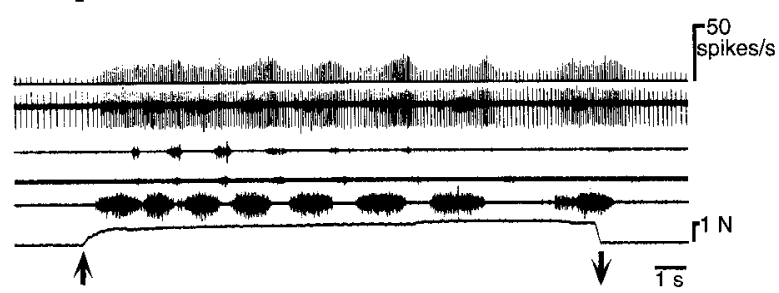

Figure 4. Example of a motor RF unit with only weakly rhythmic activity during fictive scratching evoked by ipsilateral or contralateral stimulation. $A$, Axon recording location. $B 1$ and $B 2$, Ipsilateral and contralateral unit excitatory receptive fields, respectively. $C-F$, Glass probe mechanical stimulation at the following sites: $C$, ipsilateral SP3; $D$, ipsilateral femoral $10 ; E$, contralateral SP3; $F$, contralateral femoral 8 . Other conventions are as in previous figures.

(Fig. 2D). Six (75\%) of the eight unisegmental RF units recorded were classified as slowly adapting. During mechanical stimulation that evoked fictive pocket scratching within the unit's excitatory receptive field (Fig. $2 D$ ), the illustrated unit's activity showed no apparent rhythmic modulation; its activity was not statistically distinguishable from random activity within the ipsilateral VP-HP nerve activity cycle ( $p>0.04$ by the Rayleigh test; see Materials and Methods and Berkowitz and Stein, 1994b). This unit was active for several seconds following the cessation of strong stimulation within its most sensitive region (Fig. 2D2). Such long afterdischarge was common among slowly adapting units (see also Currie and Stein, 1990, 1992). Of 84 units (in all receptive field categorics) classificd as slowly adapting, $68(81 \%)$ were active (at a higher rate than their spontaneous level) for more than $2 \mathrm{sec}$ following cessation of a stimulus.

Multisegmental receptive field unit. A multisegmental RF unit is illustrated in Figure 3. This unit's excitatory receptive field (Fig. $3 B$ ) included portions of both the rostral scratch and the pocket scratch receptive fields, on both sides of the body, but did not include the most anterior (rostral) part of the rostral scratch receptive field on either side of the body. Stimulation in the pocket scratch receptive field or the posterior portion of the rostral scratch receptive field evoked unit activity during the stimulation on all trials (Fig. $3 D, E, G, H$ ); the unit was also active after the stimulation on some trials (Fig. $3 E, G, H$ ). Stimulation in the anterior portion of the unit's excitatory receptive field on either side elicited unit activity during stimulation on most trials, but elicited activity only after stimulation on other trials (Fig. $3 C, F$ ), perhaps via inhibitory rebound. This suggests that there may be an inhibitory component to the unit's response to stimulation of these regions. Inhibition was demonstrated for one ipsilateral site anterior to the unit's excitatory receptive field (indicated by a solid triangle in Fig. $3 B I$ ), using two-site stimulation (see below and Fig. $8 B$ ). This unit showed rhythmic modulation of its activity during both rostral and pocket fictive scratching, both ipsilaterally and contralaterally $(p<0.001$ by the Rayleigh test, for at least one site in the rostral and pocket scratch receptive fields, both ipsilaterally and contralaterally). The unit's activity began at very long latency, well after the onset of motor activity.

Motor receptive field units. Examples of motor RF units are illustrated in Figures 4-6. Most such units were active throughout the stimulation, with some degree of rhythmic modulation, during fictive rostral scratching or fictive pocket scratching evoked by ipsilateral or contralateral stimulation (e.g., Figs. 4, 5). Figure 4 shows such a unit near the nonrhythmic end of the 


\section{B1 IPSI. RECEPTIVE FIELD}

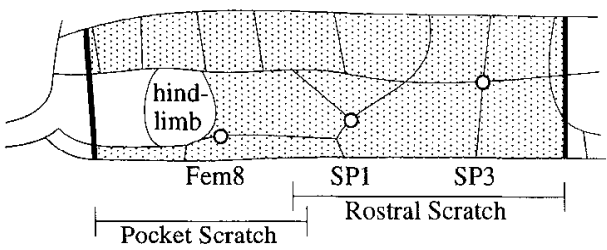

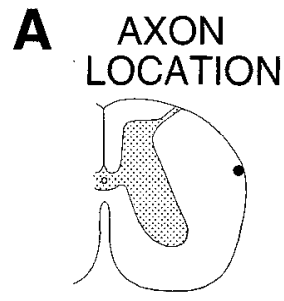

B2 CONTRA. RECEPTIVE FIELD

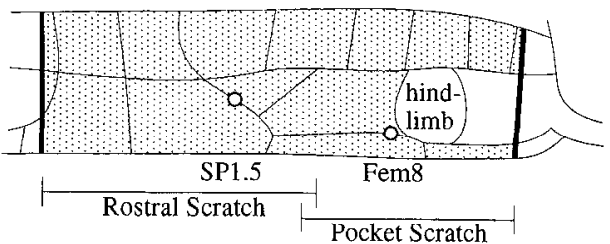

C IPSI. Rostral scratch

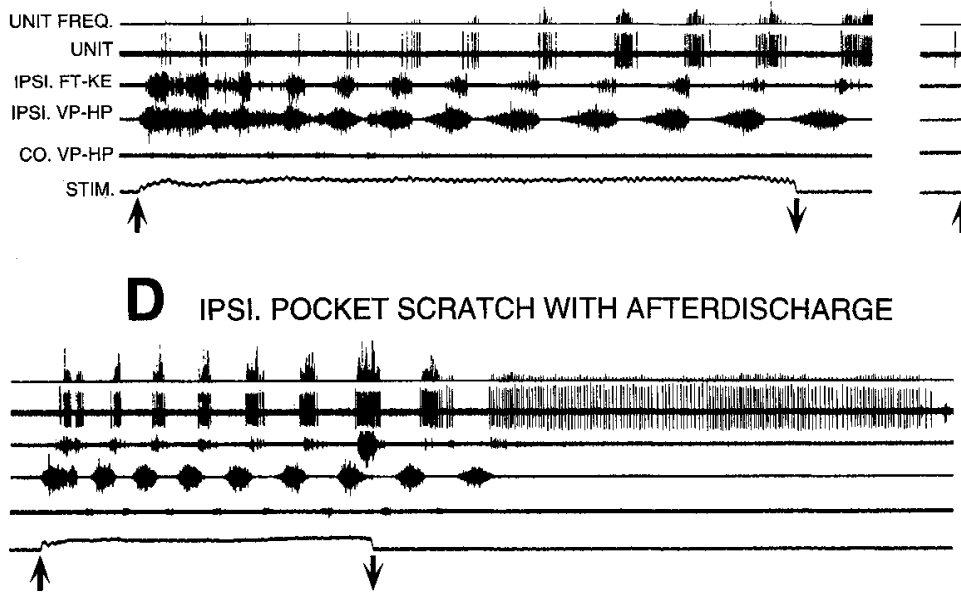

E CONTRA. ROSTRAL SCRATCH

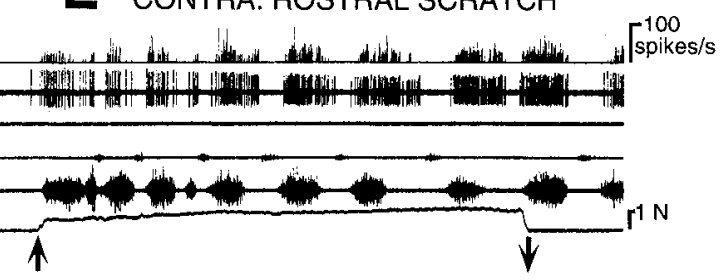

F CONTRA. POCKET SCRATCH

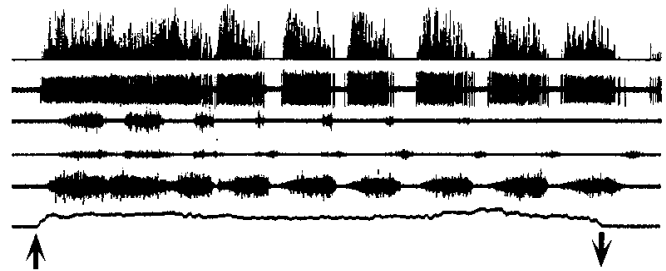

G IPSI. Rostral SCRatch With afterdischarge

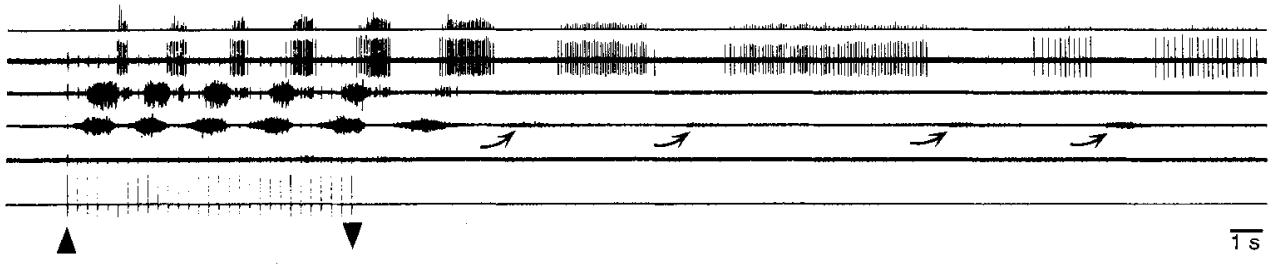

Figure 5. Example of a motor RF unit with strongly rhythmic activity during fictive scratching evoked by ipsilateral or contralateral stimulation $A$, Axon recording location. $B I$ and $B 2$, Ipsilateral and contralateral unit excitatory receptive fields, respectively. $C-F$, Glass probe mechanical stimulation at the following sites: $C$, ipsilateral $\mathrm{SP} 1 ; D$, ipsilateral femoral $8 ; E$, contralateral SP1.5; $F$, contralateral femoral 8 ; $G$, unit and muscle nerve responses to a train of electrical stimuli delivered to the ipsilateral SP3 shell. Ten volt, $1 \mathrm{msec}$ stimuli were delivered at $3 \mathrm{~Hz}$. $\Delta$, $\nabla$, onset and offset of stimulus train. Curved arrows indicate weak bursts in the ipsilateral VP-HP nerve during rhythmic unit afterdischarge. STIM., stimulus trace. Other conventions are as in previous figures.

spectrum; its activity was never more than weakly rhythmically modulated (Fig. $4 C-F ; p>0.07$ by the Rayleigh test at all sites; mean vector length $=0.01-0.17$ at all sites; see Materials and Methods and Berkowitz and Stein, 1994b). Several very small units that were rhythmically activated are also visible in some of these recordings (Fig. 4C,E,F). The top trace in each set is the instantaneous firing rate of the large unit only; the unit was isolated using a window discriminator. This unit had spontaneous activity, but it clearly increased its firing rate during stimulation and for several seconds afterwards, even following the cessation of recorded motor activity (Fig. $4 C-F$ ). It responded to stimulation of each of the D4-D6 nerves at a latency of 18 $40 \mathrm{msec}$ and to D7 nerve stimulation at a latency of $25-85 \mathrm{msec}$ (data not shown), although it was spontaneously active at only about $5 \mathrm{~Hz}$ (i.e., one spike every $200 \mathrm{msec}$ ). It also increased its firing rate in response to a single electrical stimulus to the shell or skin ipsilaterally (data not shown), beginning at 100 msec or more. Its response to successive electrical stimuli increased (i.e., it showed temporal summation), provided that the stimuli were $<700$ msec apart.

In contrast, the unit illustrated in Figure 5 showed strong rhythmic modulation during both forms of fictive scratching, 


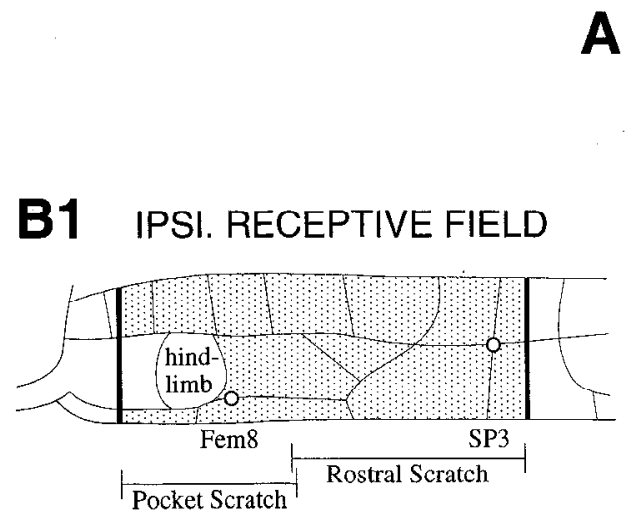

\section{AXON \\ LOCATION}

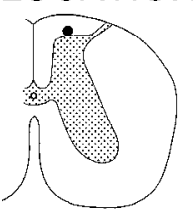

B2 CONTRA. RECEPTIVE FIELD
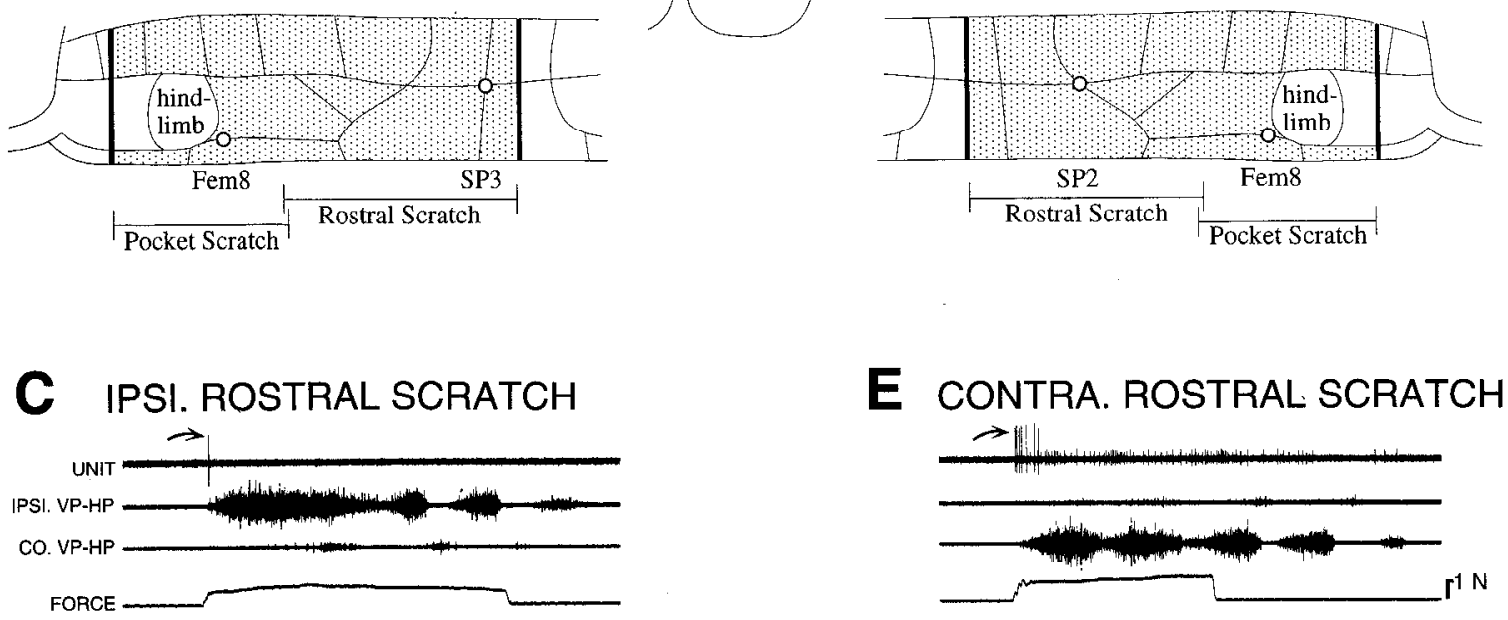

\section{IPSI. POCKET SCRATCH}
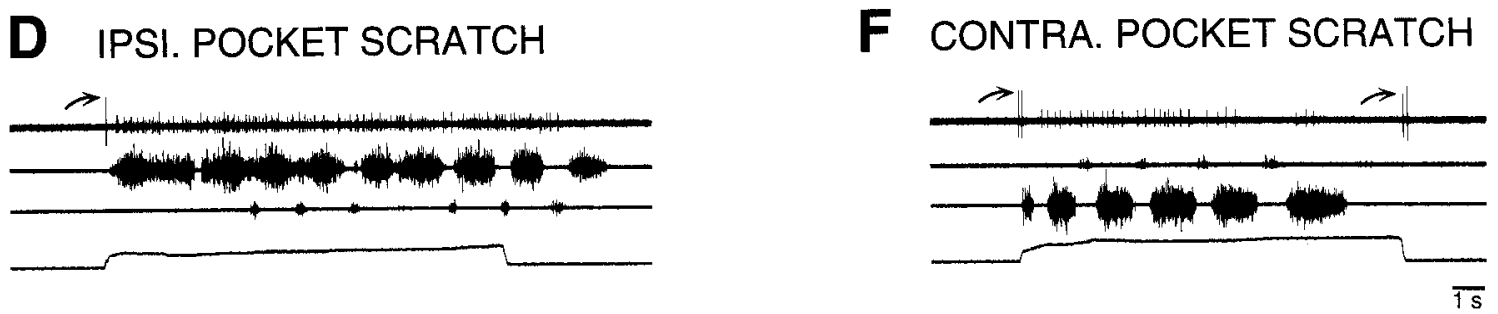

Figure 6. Example of a motor RF unit with rapidly adapting activity in response to stimulation in the rostral scratch or pocket scratch receptive field, ipsilaterally or contralaterally. $A$, Axon recording location. $B 1$ and $B 2$, Ipsilateral and contralateral unit excitatory receptive fields, respectively. $C-F$, Glass probe mechanical stimulation at the following sites: $C$, ipsilateral SP3; $D$, ipsilateral femoral $8 ; E$, contralateral SP2; $F$, contralateral femoral 8. Other conventions are as in previous figures.

both ipsilaterally and contralaterally (Fig. $5 C-F ; p<0.001$ by the Rayleigh test at all sites; mean vector length $=0.47-0.89$ for ipsilateral fictive scratching; mean vector length $=0.15-0.73$ for contralateral fictive scratching). This unit often fired a burst of spikes in response to an electrical stimulus to any of the D5D7 nerves (data not shown), but at a latency of at least $2 \mathrm{sec}$, well after motor activity had begun. It could also be activated by electrical stimulation of the shell, at similarly long latencies (e.g., Fig. $5 G$ ). It showed temporal summation of its activity in response to ipsilateral rostral scratch electrical shell stimuli as much as $5 \mathrm{sec}$ apart (data not shown). For nine units in the study (one unisegmental RF unit, two multisegmental RF units, and six motor RF units), temporal summation was demonstrated in response to electrical shell or skin stimuli at least $1 \mathrm{sec}$ apart (see also Currie and Stein, 1990, 1992). The illustrated unit was active for many seconds following the end of stimulation in the rostral scratch or pocket scratch receptive fields (Fig. 5D,G). In some cases, this long afterdischarge appeared to be nonrhythmic and continued after the cessation of recorded motor activity (Fig. 5D; see also Currie and Stein, 1990). In most cases, however, this long afterdischarge was clearly rhythmic (Fig. $5 G$ ). When descending propriospinal units showed rhythmic afterdischarge, it was usually accompanied by weak, rhythmic activity in at least one recorded muscle nerve (e.g., Fig. $5 G$ ).

Only eight units in the study were classified as rapidly adapting. One such unit is illustrated in Figure 6. This unit was also a motor RF unit, one of only two rapidly adapting motor RF units. It was excited by stimulation in the rostral scratch or pocket scratch receptive field on either side of the body, but usually fired only at the onset of stimulation; occasionally, the unit also fired at the offset of stimulation, even if the recorded motor activity had ceased (Fig. $6 F$ ). By contrast, a small, slowly adapting unit in the same recording fired throughout the stimulation (Fig. 6D-F).

Dual-latency unit. For three multisegmental RF units and six motor RF units, it was found that the unit responded at long latency to stimulation in most of its excitatory receptive field, but responded at much shorter latency to stimulation within a particular subregion of its excitatory receptive field. An example of such a dual-latency unit is illustrated in Figure 7. This unit was excited during both rostral and pocket fictive scratching, both ipsilaterally and contralaterally (Fig. $7 B, G-J$ ). In most locations, the unit responded to mechanical stimulation at a latency of $>70 \mathrm{msec}$ (Fig. $7 G, I, J)$. However, within the ventral shell regions of the pocket scratch receptive field ipsilaterally, 


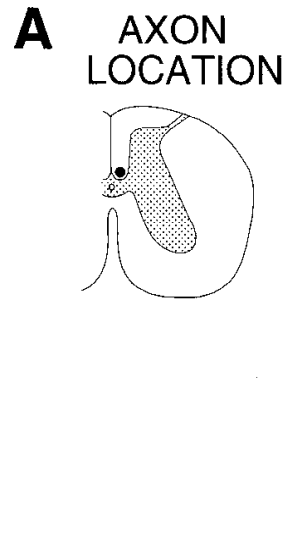

\section{B2 CONTRA. RECEPTIVE FIELD}
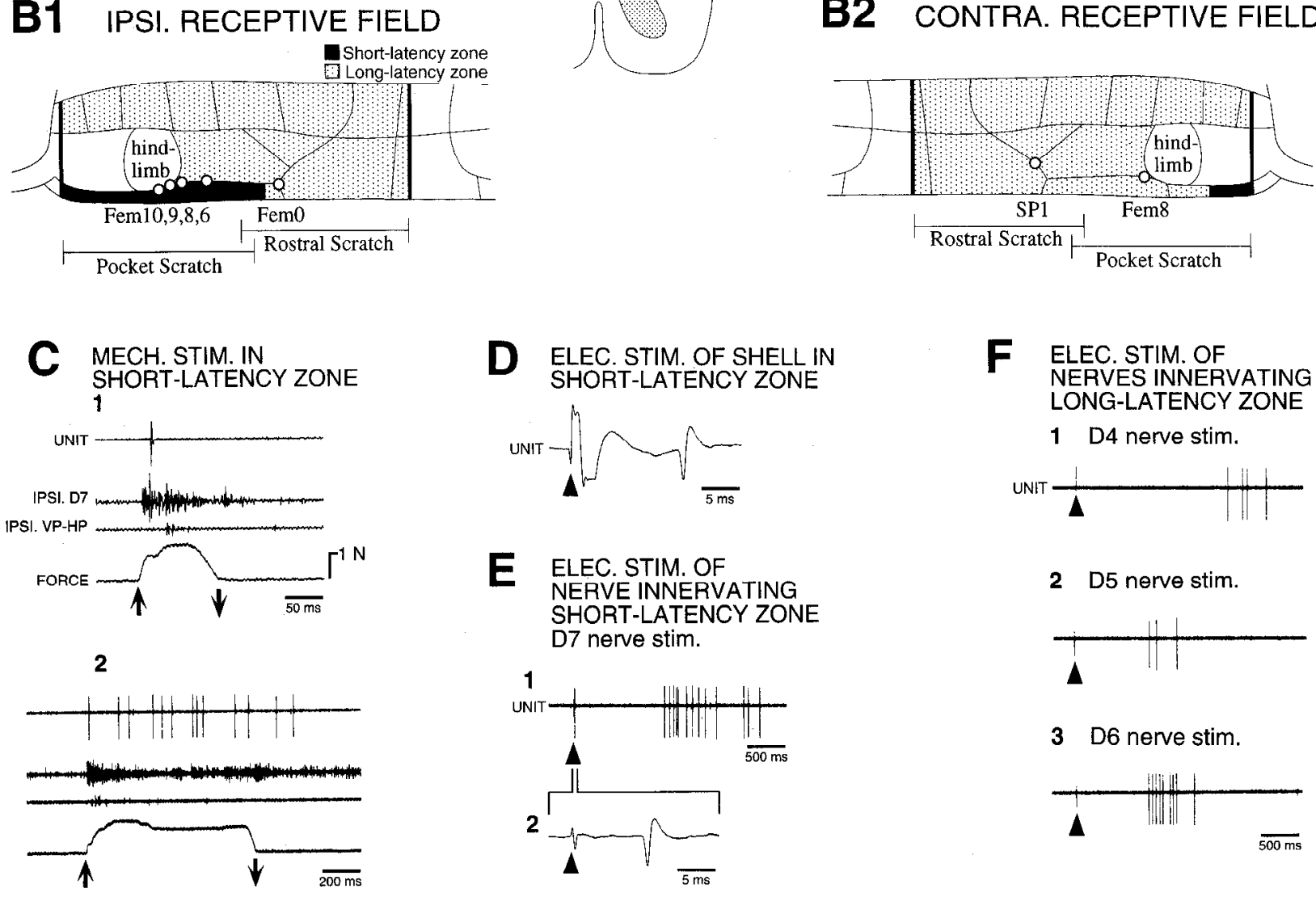

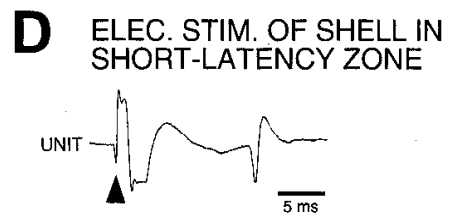
E ELEC. STIM. OF NERVE INNERVATING SHORT-LATENCY ZONE D7 nerve stim.

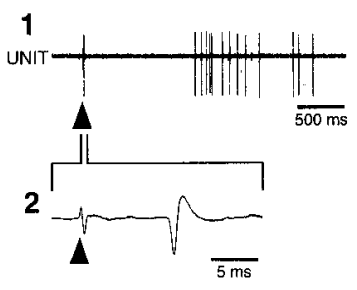

\section{F ELEC. STIM. OF NERVES INNERVATING LONG-LATENCY ZONE}

1 D4 nerve stim.

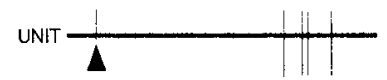

2 D5 nerve stim.

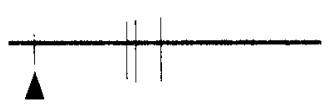

3 D6 nerve stim.

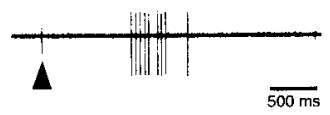

\section{G IPSI. ROSTRAL SCRATCH}

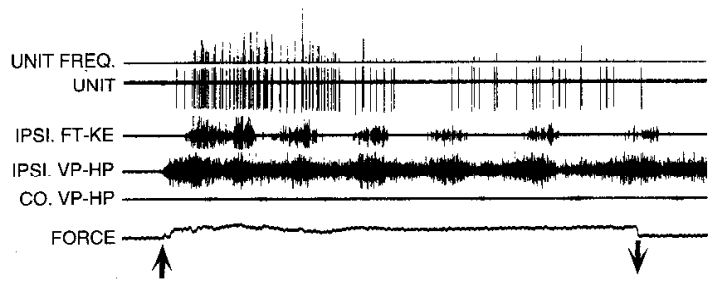

H IPSI. POCKET SCRATCH
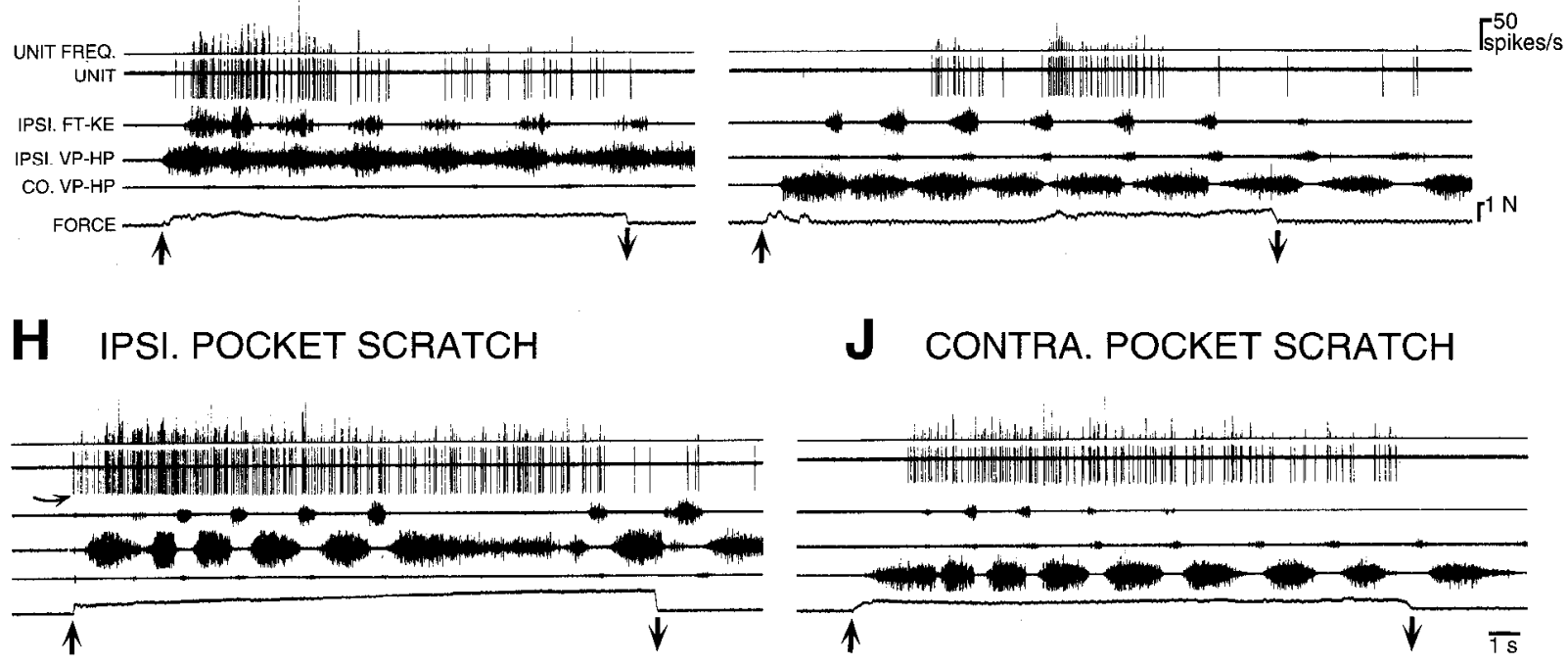

J CONTRA. POCKET SCRATCH

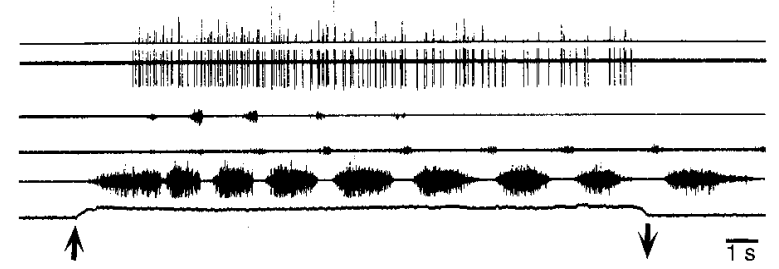

Figure 7. Example of a motor RF unit with a dual-latency receptive field. $A$, Axon recording location. $B 1$ and $B 2$, Ipsilateral and contralateral unit excitatory receptive fields, respectively. Stimulation in the solid (short-latency) zone evoked unit activity at a latency of $<25$ msec. Stimulation in the stippled (long-latency) zone evoked unit activity at a latency of $>70 \mathrm{msec}$. $C$, Unit, ipsilateral D7 segmental nerve, and ipsilateral VP-HP nerve responses to glass probe stimulation in the unit's short-latency zone, at ipsilateral femoral $9(1)$ and ipsilateral femoral $10(2)$. The ipsilateral D7 nerve contains the axons of primary afferents that innervated the unit's short-latency zone, in addition to respiratory motoneuron axons. $D$, Unit response to a $12 \mathrm{~V}, 1 \mathrm{msec}$ electrical stimulus to ipsilateral femoral 6 , in the unit's short-latency zone. $E$, Unit response to a $0.9 \mathrm{~V}, 50 \mu \mathrm{sec}$ 
and partly contralaterally (Fig. $7 B$ ), the unit responded to mechanical stimulation at a latency of $<25 \mathrm{msec}$ (Fig. $7 C, D, H$ ). Stimulation in this short-latency zone evoked a unit response soon after the onset of the sensory afferent burst (in the D7 nerve, which includes both primary afferent axons and respiratory motoneuron axons), and well before motor activity began (in the VP-HP nerve). Stimulation in the short-latency zone could also elicit a unit response in the absence of a motor response (data not shown). The unit response to electrical stimulation of the shell within the short-latency zone occurred reliably at a latency of 12-18 msec (Fig. $7 D$ ). For comparison, the average response latency of primary afferents to electrical stimulation of the shell is about $15 \mathrm{msec}$ (Currie and Stein, 1990). Electrical stimulation of the shell in the long-latency zone evoked responses at latencies of $>100 \mathrm{msec}$. A similar set of results was obtained by stimulation of the D4-D7 nerves. Each stimulus to the D7 nerve, which innervated much of the shortlatency zone, evoked a spike at 9-11 msec, in addition to a burst of spikes at $>1 \mathrm{sec}$ (Fig. $7 E$ ). In contrast, a stimulus to the D4, D5, or D6 nerves, which innervated only the long-latency zone, evoked just a burst of unit spikes at a latency of $>1 \mathrm{sec}$ (Fig. $7 F$ ). This unit's activity showed weak rhythmic modulation during fictive scratching $(p<0.01$ by the Rayleigh test for ipsilateral pocket scratching and contralateral rostral scratching only). Of the nine identified dual-latency units, eight showed some degree of rhythmic modulation for at least some stimulation sites.

A number of tests had to be applied to demonstrate that a unit had a dual-latency receptive field. Many unit recordings were not maintained for long enough to perform all of these tests. Hence, it is likely that the number of such units recorded in this study was greater than the nine that were so identified. The receptive fields of other multisegmental RF or motor RF units with long-latency excitatory responses may have included small short-latency zones that were not detected during the experiment. In addition, during fictive scratching, unisegmental RF units might also have received long-latency depolarization that was subthreshold for spike generation; such excitation can best be detected by intracellular recording (Woolf and King, 1989).

\section{Latencies of response to electrical stimulation}

During recordings from 35 units, one or more segmental nerves that innervated the unit's excitatory receptive field were stimulated with a single electrical pulse. Unit response latencies of 6-20 msec to a nerve stimulus were found in 14 units; of these 14 , three were unisegmental RF units, six were multisegmental RF units, and five were motor RF units. Two of these five motor RF units had dual-latency receptive fields and responded at short latency to stimulation only of the nerve that innervated the short-latency zone. Nerve stimulation latencies were always $>20 \mathrm{msec}$ in an additional 17 units; of these 17, four were multisegmental RF units and 13 were motor RF units. Thus, there was a tendency for units with smaller excitatory receptive fields to respond to a nerve stimulus at shorter latency. The remaining four units (one multisegmental RF unit and three motor RF units) showed no response to an electrical stimulus to nerves innervaling the unit's excitatory receptive field. In addition, one inhibited-only unit showed no response to nerve stimulation. Another inhibited-only unit (with spontaneous activity) showed no clear response to a single nerve stimulus but displayed a distinct burst of activity following each nerve stimulus in a $1 \mathrm{~Hz}$ train of nerve stimuli.

During recordings from 25 units, we were able to activate the unit using an electrical stimulus to the shell or skin within the unit's excitatory receptive field. Four $(16 \%)$ of these units responded to the electrical stimulus with a $12-30$ mscc latency; of these four, one was a unisegmental RF unit, one was a multisegmental RF unit, and two were motor RF units. The remaining 21 units (84\%) responded with a latency of $>30 \mathrm{msec}$; of these 21 , one was a unisegmental RF unit, eight were multisegmental RF units, and 12 were motor RF units.

\section{Inhibition}

Of the 104 units recorded, $36(35 \%)$ displayed spontaneous activity. Of these 36 units, $16(44 \%)$ were inhibited by tactile stimulation of at least one site in the rostral scratch or pocket scratch receptive field. Of these 16 , four were multisegmental RF units and eight were motor RF units, in addition to the four inhibited-only units. Inhibition could be complete and apparently nonrhythmic (Fig. 8A1) or it could be rhythmic (Fig. 8A2). The remaining 68 units recorded $(65 \%)$ did not show spontaneous activity. In some of these cases, a site inside the unit's excitatory receptive field was stimulated, and, during this period, a site outside the unit's excitatory receptive field was also stimulated (two-site stimulation; Fig. $8 B$ ). If the unit's response to the excitatory stimulus was reduced during the two-site stimulation, it was concluded that the second site was inhibitory. For seven units without spontaneous activity, the existence of an inhibitory site or sites in the rostral scratch or pocket scratch receptive field was demonstrated using two-site stimulation (Fig. $8 R$ ). Of these seven units, one was a unisegmental RF unit, four were multisegmental RF units, and two were motor RF units. In some units that had a unilateral excitatory receptive field, inhibitory sites were found ipsilateral to the excitatory receptive field; in other units, inhibitory sites were found contralaterally or bilaterally.

\section{Firing rates within unit excitatory receptive fields}

Twenty-one $(20 \%)$ of the descending propriospinal neurons studied had an excitatory receptive field confined to either the rostral scratch or the pocket scratch receptive field, on at least one side of the body. One of these units had an excitatory receptive field that closely matched the ipsilateral pocket scratch receptive field and one had an excitatory receptive field that closely matched the contralateral rostral scratch receptive field. In contrast, $79(76 \%)$ of the units studied had an excitatory receptive field that included parts of both the rostral scratch and

electrical stimulus to the ipsilateral D7 nerve, shown at slow sweep speed (1), and fast sweep speed (2), to illustrate the initial unit response to the stimulus. $F$, Unit response to electrical stimulation of the ipsilateral D4 nerve with a $6 \mathrm{~V}, 50 \mu \mathrm{sec}$ stimulus (l), the ipsilateral D5 nerve with a 6 $\mathrm{V}, 50 \mu \mathrm{sec}$ stimulus (2), and the ipsilateral D6 nerve with a $1.5 \mathrm{~V}, 50 \mu \mathrm{sec}$ stimulus (3). The D4, D5, and D6 nerves contain the axons of primary afferents that innervated the unit's long-latency zone. $G-J$, Glass probe mechanical stimulation at the following sites: $G$, ipsilateral femoral 0 ; $H$, ipsilateral femoral $8 ; I$, contralateral SPI; $I$, contralateral femoral 8 . Curved arrow in $H$ indicates the first action potential in the unit. Other conventions are as in previous figures. 


\section{A INHIBITION OF SPONTANEOUS DISCHARGE 1 Tonic inhibition}

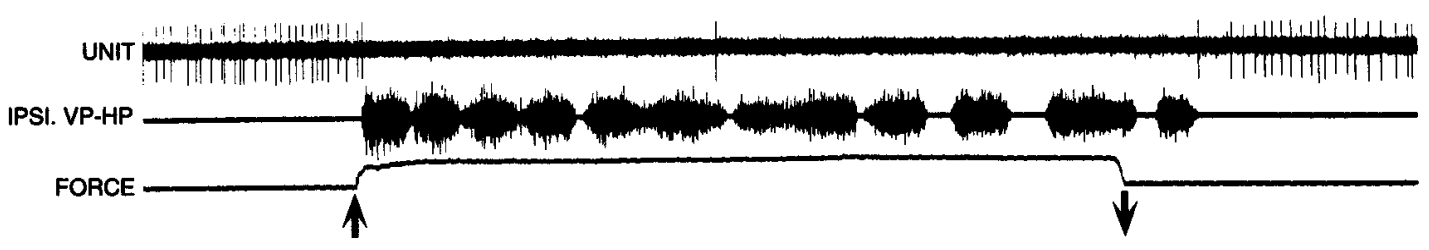

2 Rhythmic inhibition

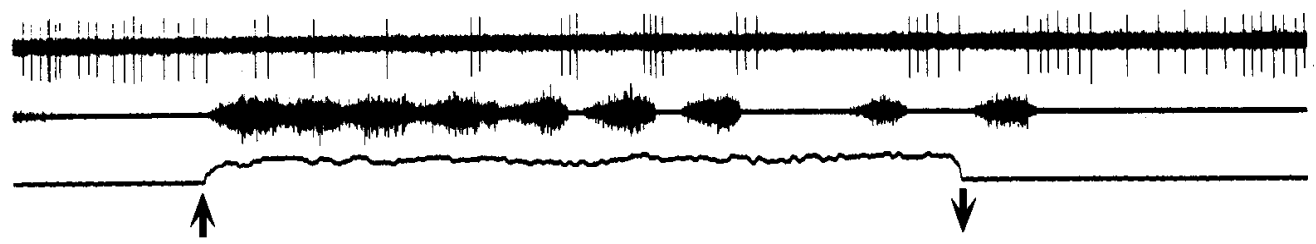

\section{B INHIBITION SHOWN WITH 2-SITE STIMULATION}

1 Mech. stim. in excitatory zone

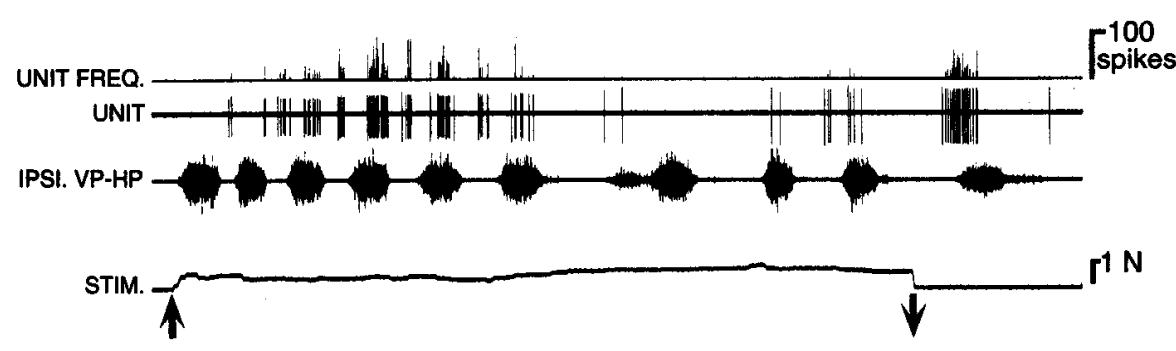

2 Elec. stim. in inhibitory zone

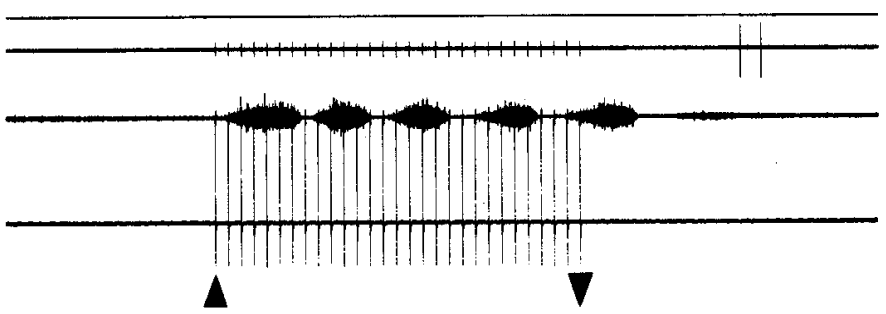

3 Elec. stim. in inhibitory zone during mech. stim. in excitatory zone

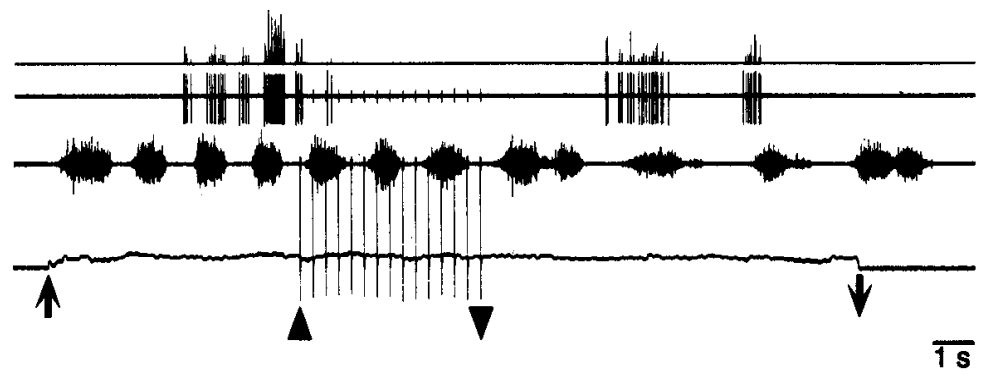

Figure 8. Demonstration of inhibitory sites in unit receptive fields. $A$. Inhibition of a spontaneously active unit during stimulation with a glass probe. Inhibition could be nearly complete and apparently tonic $(A 1)$ or it could be rhythmic $(A 2)$. Stimulation was delivered to contralateral 
A Recordings
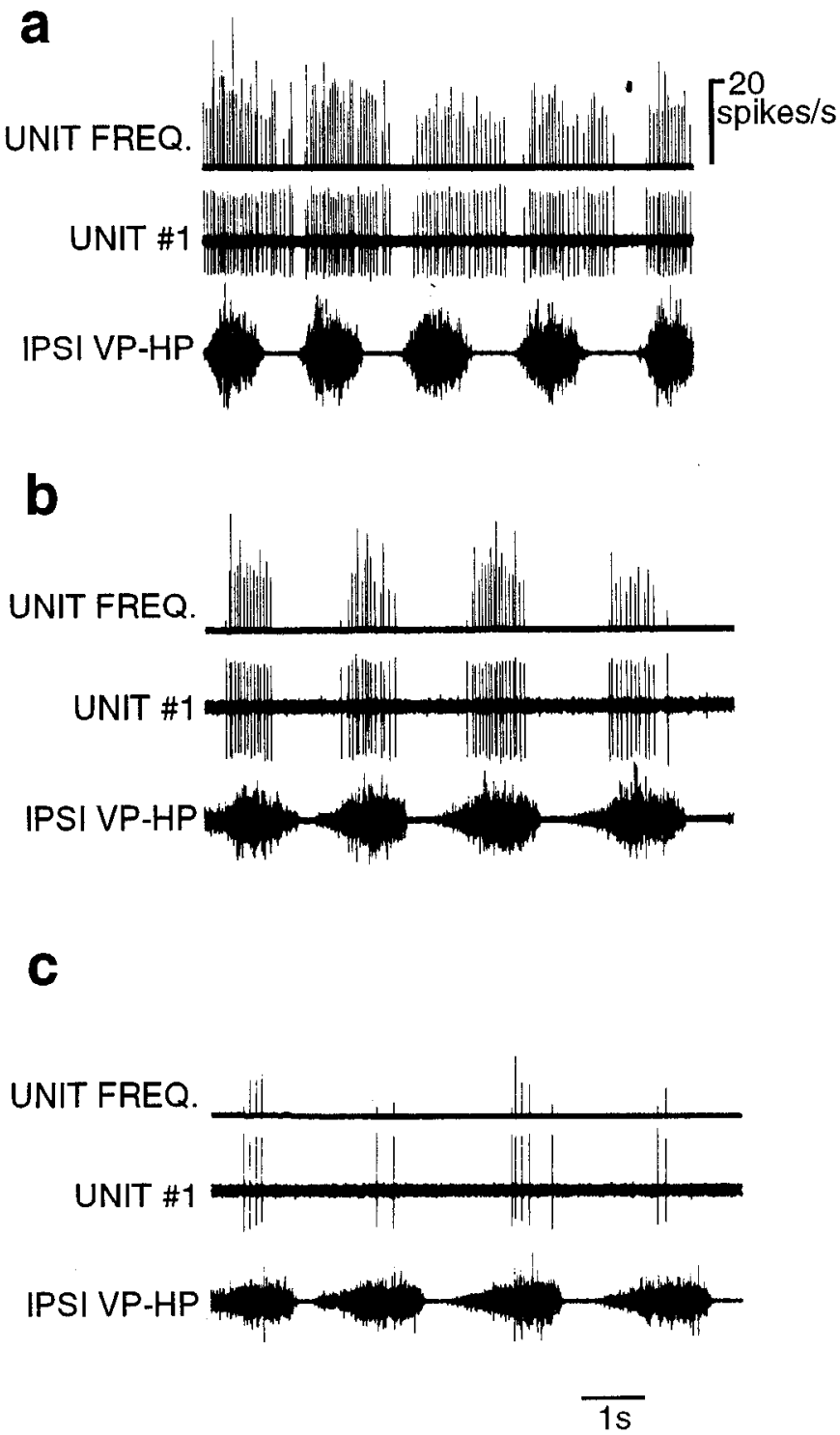

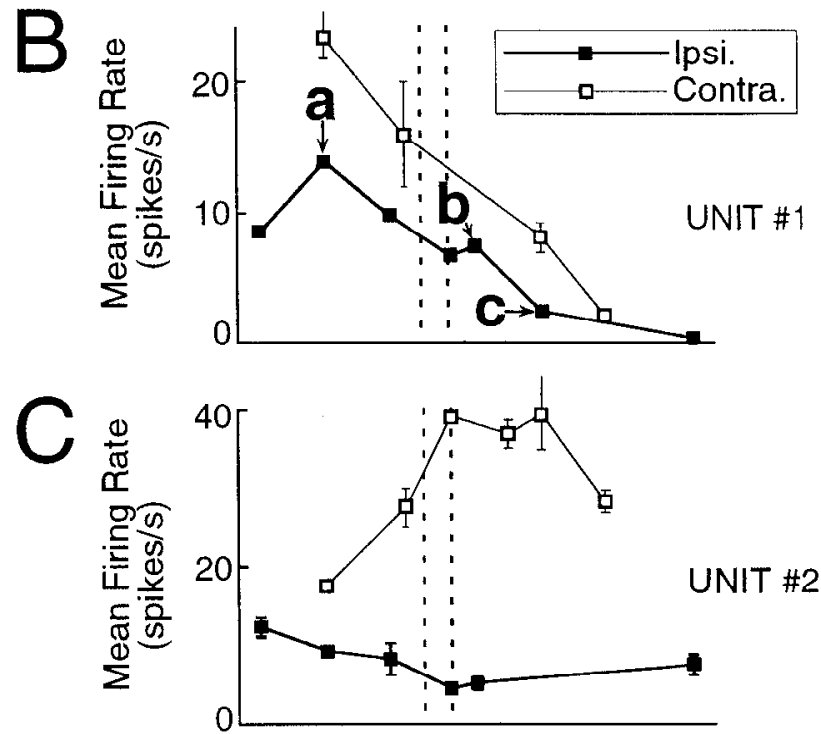

1

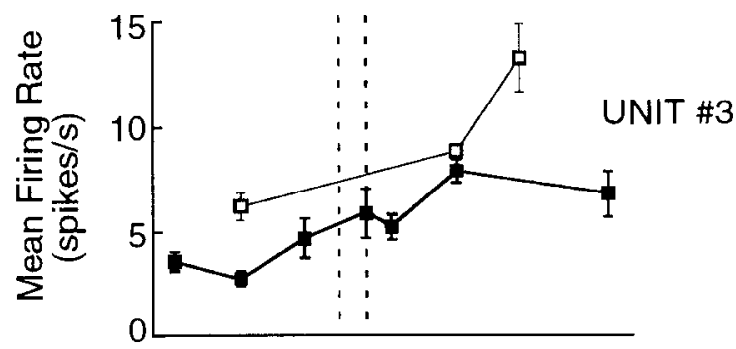

E

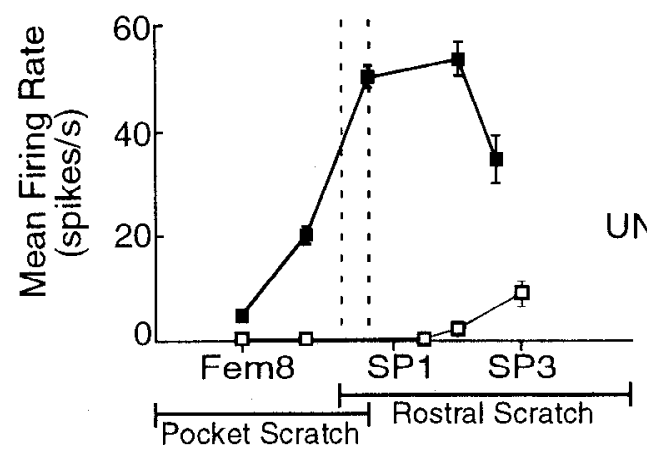

Figure 9. Broad tuning of units to regions of the body surface. $A$, Responses of one unit to stimulation of three sites in its ipsilateral excitatory receptive field: $a$, femoral $8 ; b, \mathrm{SP} 1$; and $c, \mathrm{SP} 2 . B-E$, Graphs of unit mean firing rate as a function of site stimulated across the pocket scratch and rostral scratch receptive fields for four motor RF units recorded in the same animal. $B$ shows the graph for the unit illustrated in $A$; the points $a-$ $C$ are the firing rates for the sites stimulated in $A a-A c$, respectively. Vertical dashed lines indicate the transition zone between the pocket scratch and rostral scratch receptive fields. Error bars indicate SEM. See Materials and Methods for procedures used in calculation of mean firing rates. Ipsi., ipsilateral; contra., contralateral.

the pocket scratch receptive fields. In order to examine whether these neurons might nevertheless be involved in scratch form selection, we calculated the unit mean firing rate at several sites within the unit's excitatory receptive field, for all units $(n=13)$ for which sufficient data were available (see Materials and Methods). Figure $9 B-E$ shows unit firing rates across the pocket scratch and rostral scratch receptive fields for four motor RF units, all from the same animal. Each of these units was excited both

femoral 8 , in the pocket scratch receptive field $(A I)$, and contralateral SP3, in the rostral scratch receptive field $(A 2)$, while recording from the same unit. This unit was a motor RF unit; it was excited by ipsilateral stimulation and inhibited by contralateral stimulation. $B$, Inhibition of a different unit, demonstrated by two-site stimulation. This is the same unit as illustrated in Figure 3. B1, Stimulation with a glass probe in the unit's excitatory receptive field, at ipsilateral femoral 8 . B2, Stimulation with a train of electrical stimuli to the shell at an inhibitory site, ipsilateral SP3 (indicated by $\nabla$ in Fig. $3 B I$ ). Ten volt, $1 \mathrm{msec}$ stimuli were delivered at $3 \mathrm{~Hz}$. B3, Electrical stimulation of the shell at the inhibitory site (same parameters as in $B 2$ ) during glass probe stimulation in the unit's excitatory receptive field (same parameters as in B1). The unit response to the excitatory stimulation was reduced during the inhibitory stimulation. Other conventions are as in previous figures. 
A Unisegmental RF units

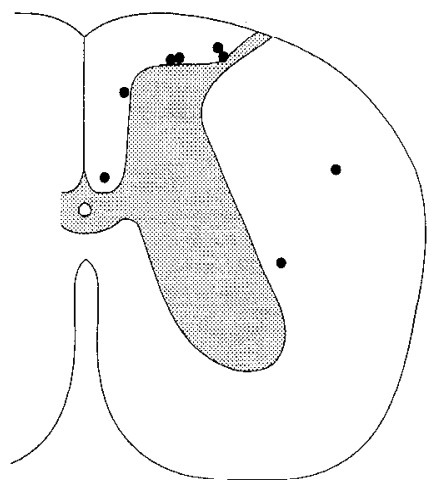

Bultisegmental RF units

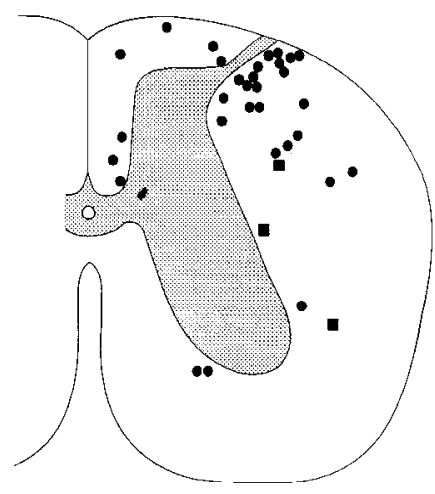

C

Motor RF units
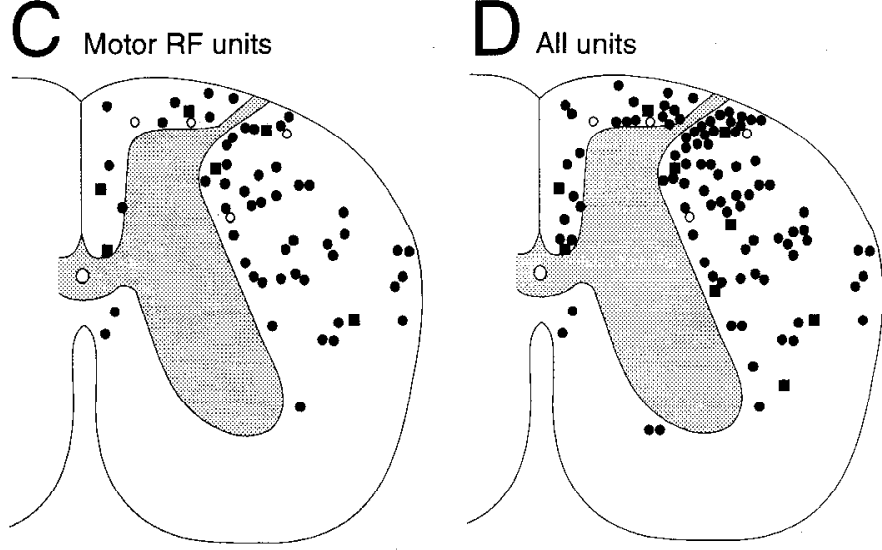

Figure 10. Recording locations for descending propriospinal axons in this study, marked on sketches of cross sections of the caudal D9 spinal cord. $A$, Unisegmental RF units. $B$, Multisegmental RF units. $C$, Motor RF units and inhibited-only units. $D$, All units. $O$ in $C$ and $D$ represent inhibited-only units. $\square$ in $B-D$ represent dual-latency units. All other units with excitatory receptive fields are represented by $\bullet$. The ventral funiculus and ventral part of the lateral funiculus were seldom sampled (see Materials and Methods).

ipsilaterally and contralaterally throughout the rostral scratch and pocket scratch receptive fields. However, instead of firing spikes at about the same rate for each site within the unit's excitatory receptive field, each of these units showed a very clear and progressive change in its firing rate as a function of the site stimulated. In most cases, the unit firing rate was maximal for one region and steadily declined for stimulation of sites farther away from that region ("positive tuning"; Fig. $9 B, D, E$ both ipsilaterally and contralaterally, $C$ contralaterally). In other words, these units showed broad tuning to a particular region of the body surface. Units could be tuned to a region within the rostral scratch receptive field (Fig. $9 D, E$ ) or a region within the pocket scratch receptive field (Fig. $9 B$ ). Since the units illustrated in Figure 9 were all recorded in the same animal, this regional tuning cannot simply reflect the relative robustness of fictive rostral scratching and fictive pocket scratching in each animal. For example, the unit illustrated in Figure $9, A$ and $B$, was most strongly activated following stimulation at femoral 8 (Fig. 9 $\mathrm{Aa}$ ), in the pocket scratch receptive field, and was progressively less strongly activated following stimulation at more anterior sites (Fig. $9 A b, A c$ ) in the rostral scratch receptive field. The amplitudes of the bursts of activity in the ipsilateral VP-HP nerve were also greater in fictive pocket scratching (Fig. $9 \mathrm{Aa}$ ) than in fictive rostral scratching (Fig. 9Ab, $A C$ ). However, the amplitudes of the VP-HP bursts were greater for fictive pocket scratching than fictive rostral scratching throughout the recordings obtained in this animal, whereas other propriospinal units recorded in this animal were positively tuned to regions of the rostral scratch receptive field (Fig. $9 D, E$ ). Tuning curves were often similar for the two sides of the body (Fig. $9 B, D$ ). In some cases, the unit firing rate was minimal for stimulation of one region and steadily increased for sites farther away from that region in either direction ("negative tuning"; Fig. 9C ipsilaterally).

Firing rate was calculated as a function of stimulation site for two multisegmental RF units and 11 motor RF units. Both of the multisegmental RF units and nine of the 11 motor RF units showed clear positive tuning to a particular region of the body surface either ipsilaterally or contralaterally. The remaining two motor RF units showed clear negative tuning to a particular region. Eight of these motor $\mathrm{RF}$ units were excited by either ipsilateral or contralateral stimulation. Five were positively tuned to the same region of the body surface on the two sides (e.g., Fig. $9 B, D, E)$; two were positively tuned to a certain region on one side and negatively tuned to a similar region on the opposite side (e.g., Fig. 9C); the remaining unit was negatively tuned to the same region on both sides. Three of the motor RF units were excited only by ipsilateral stimulation. Two of these showed positive tuning and the other showed negative tuning. One of the 13 units tested had an ipsilateral tuning curve that peaked in the region of overlap between the rostral scratch and pocket scratch receptive fields (the transition zone; see Mortin et al., 1985). The remaining 12 units fired at their highest rate for stimulation within either the rostral scratch or the pocket scratch receptive field, on both sides. No unit tested showed approximately the same firing rate throughout the unit's excitatory receptive field. No unit tested showed apparently random fluctuations in firing rate as a function of site. No unit tested was positively tuned to a region within one scratch form receptive field on one side of the body and positively tuned to a region within the other scratch form receptive field on the opposite side of the body.

\section{Axon locations}

Descending propriospinal axons were found in all regions of the white matter that were sampled (Fig. 10D). Axons were seldom recorded from the ventral funiculus or ventralmost lateral funiculus, due to technical limitations (see Materials and Methods). Many descending propriospinal axons were recorded both near and far from the gray matter in the dorsal funiculus and the lateral funiculus. Unisegmental RF units were concentrated in the dorsal funiculus, near the gray matter, but could also be found in the lateral funiculus (Fig. 10A). Multisegmental RF units were found in both the dorsal funiculus and lateral funiculus, but were concentrated dorsally (Fig. 10B). Motor RF units appeared to be evenly distributed throughout the dorsal funiculus and lateral funiculus (Fig. 10C).

\section{Discussion}

The central finding of this study was that most descending propriospinal neurons recorded in the turtle hindlimb enlargement were excited by tactile stimulation anywhere within the rostral scratch or pocket scratch receptive fields on at least one side of the body; yet many of these neurons were broadly tuned to a particular region of the body surface, as assessed by calculation of their mean firing rates for different stimulation sites. Some 
were tuned to a region of the rostral scratch receptive field while others were tuned to a region of the pocket scratch receptive field, even among neurons recorded in the same animal. These data are consistent with the hypothesis that spinal selection of an appropriate form of scratching is mediated by populations of broadly tuned neurons, rather than by neurons that individually carry sufficient information to select reliably an appropriate form of scratching. The hypothesis that populations of broadly tuned neurons mediate motor pattern selection has been advanced for visual control of eye and head movements by the primate superior colliculus (Sparks et al., 1976) and for visual control of directed arm movements by the primate motor cortex (Georgopoulos et al., 1982). There is strong evidence for this hypothesis in both systems (e.g., Lee et al., 1988; Schwartz et al., 1988; Georgopoulos et al., 1993). Also, it has recently been shown that dorsal spinocerebellar tract neurons are broadly tuned to particular directions of passive whole-limb movement in the cat (Bosco and Poppele, 1993).

An additional finding was that some descending propriospinal neurons were excited at very short latency by tactile stimulation within a particular region and excited at much longer latency by tactile stimulation within a larger region. Such neurons often generated action potentials with weak rhythmic modulation during both fictive rostral scratching and fictive pocket scratching. Unit responses to stimulation in the short-latency region began well before motor activity, and in some cases in the absence of motor activity. Thus, each of these neurons had separable sensory-related and motor-related response components. One possibility is that such ncurons received direct or indirect inputs from primary afferents, as well as rhythmically modulated feedback from scratch pattern-generating neurons. If so, these neurons could be thought of as sensory interneurons that are modulated or gated by corollary discharge during active movements. Rhythmic feedback from vertebrate motor patterngenerating neurons to primary afferents or spinal interneurons has been found in several species (Arshavsky et al., 1972, 1978; Feldman and Orlovsky, 1975; Deliagina and Orlovsky, 1980; Pratt and Jordan, 1987; Dubuc et al., 1988; Gossard et al., 1989, 1991; Sillar, 1989; Hishinuma and Yamaguchi, 1990; Shefchyk et al., 1990; Sillar and Roberts, 1992). A second possibility is that these neurons contribute to early tactile processing of a small region and also contribute to scratch motor pattern generation via projections to motoneurons or other pattern-generating neurons. In this case, such neurons would effectively be members of two populations of spinal ncurons, cach population with a distinct function. Knowledge of the projections of these neurons will be required to evaluate these two hypotheses.

Many descending propriospinal axons were also excited by tactile stimulation of either side of the body. Many of these neurons displayed rhythmically modulated activity during fictive scratching of either hindlimb. This was somewhat surprising, because most studies of scratching have focused on the ipsilateral spinal circuitry. Nonetheless, when unilateral tactile stimulation evokes fictive scratching in the muscle nerves of the ipsilateral hindlimb, muscle nerves of the contralateral hindlimb are often rhythmically activated (Figs. 3-7; see also Currie and Stein, 1989, their Fig. $5 C-D$ ). The activity in the right VP-HP (hip flexor) nerve usually alternates with the activity in the left VP-HP nerve. Thus, the rhythmic activity seen in many descending propriospinal axons in response to stimulation of either side may be the result of feedback from pattern-generating neurons that activate certain muscle nerves during fictive scratching evoked on either side. In addition, if some of the recorded neurons contributed to scratch motor pattern generation, it may be that descending propriospinal neurons can contribute to the generation of scratch motor patterns evoked by stimulation on the opposite side of the body. If this is the case, synaptic interactions between the two sides of the spinal cord may generally play an important role in the generation of scratch motor patterns. These possibilities are examined in more detail in the following companion article (Berkowitz and Stein, 1994b).

\section{References}

Arshavsky YI, Berkinblit MB, Fukson OI, Gelfand IM, Orlovsky GN (1972) Origin of modulation in neurones of the ventral spinocerebellar tract during locomotion. Brain Res 43:276-279.

Arshavsky YI, Gelfand IM, Orlovsky GN, Pavlova GA (1978) Messages conveyed by spinocerebellar pathways during scratching in the cat. II. Activity of neurons of the ventral spinocerebellar tract. Brain Res 151:493-506.

Berkinblit MB, Feldman AG, Fukson OI (1989) Wiping reflex in the frog: movement patterns, receptive fields, and blends. In: Visuomotor coordination (Ewert JP, Arbib MA, eds), pp 615-629. New York: Plenum.

Berkowitz A (1993) Descending propriospinal neurons in the turtle: cell body locations, funicular courses, and single-unit activity during two forms of fictive scratching. PhD thesis, Washington University, St. Louis.

Berkowitz A, Stein PSG (1990) Activity of spinal neurons with descending axons during fictive scratch in spinal turtles. Soc Neurosci Abstr 16:1091.

Berkowitz A, Stein PSG (1991) Bilateral activation of interneurons during fictive scratching in spinal turtles. Soc Neurosci Abstr 17:123.

Berkowitz A, Stein PSG (1992) Cells of origin and funicular courses of propriospinal axons descending in the turtle hindlimb enlargement. Soc Neurosci Abstr 18:312.

Berkowitz A, Stein PSG (1994a) Descending propriospinal axons in the hindlimb enlargement of the red-eared turtle: cells of origin and funicular courses. J Comp Neurol, in press.

Berkowitz A, Stein PSG (1994b) Activity of descending propriospinal axons in the turtle hindlimb enlargement during two forms of fictive scratching: phase analyses. J Neurosci 14:5105-5119.

Bosco G, Poppele RE (1993) Broad directional tuning in spinal projections to the cerebellum. J Neurophysiol 70:863-866.

Currie SN, Stein PSG (1989) Interruptions of fictive scratch motor rhythms by activation of cutaneous flexion reflex afferents in the turtle. J Neurosci 9:488-496.

Currie SN, Stein PSG (1990) Cutaneous stimulation evokes longlasting excitation of spinal interneurons in the turtle. J Neurophysiol 64:1134-1148.

Currie SN, Stein PSG (1992) Glutamate antagonists applied to midbody spinal cord segments reduce the excitability of the fictive rostral scratch reflex in the turtle. Brain Res 581:91-100.

Deliagina TG, Orlovsky GN (1980) Activity of la inhibitory interneurons during fictitious scratch reflex in the cat. Brain Res 193:439447.

Dubuc R, Cabelguen J-M, Rossignol S (1988) Rhythmic fluctuations of dorsal root potentials and antidromic discharges of primary afferents during fictive locomotion in the cat. J Neurophysiol 60:20142036.

Feldman AG, Orlovsky GN (1975) Activity of interneurons mediating reciprocal Ia inhibition during locomotion. Brain Res 84:181-194.

Georgopoulos AP, Kalaska JF, Caminiti R, Massey JR (1982) On the relations between the direction of two-dimensional arm movements and cell discharge in primate motor cortex. J Neurosci $2: 1527-1537$.

Georgopoulos AP, Taira M, Lukashin A (1993) Cognitive neurophysiology of the motor cortex. Science 260:47-52.

Gossard JP, Cabelguen JM, Rossignol S (1989) Intra-axonal recordings of cutaneous primary afferents during fictive locomotion in the cat. J Neurophysiol 62:1177-1 188.

Gossard JP, Cabelguen JM, Rossignol S (1991) An intracellular study of muscle primary afferents during fictive locomotion in the cat. $J$ Neurophysiol 65:914-926.

Grillner S, Wallen P, Brodin L, Lansner A (1991) Neuronal network generating locomotor behavior in lamprey: circuitry, transmitters, 
membrane properties, and simulation. Annu Rev Neurosci 14:169199.

Hishinuma M, Yamaguchi T (1990) Cervical interneurones oligosynaptically excited from primary afferents and rhythmically active during forelimb fictive locomotion in the cat. Neurosci Lett 111:287291.

Kunzle H, Woodson W (1983) Primary afferent projections to the spinal cord and the dorsal column nuclear complex in the turtle Pseudemys. Anat Embryol (Berl) 166:229-245.

Kupfermann I, Weiss KR (1978) The command neuron concept. Behav Brain Sci 1:3-39.

Kusuma A, ten Donkelaar HJ (1979) Staining of the dorsal root primary afferent fibers by anterograde movement of horseradish peroxidase and retrograde labelling of motoneurons and preganglionic autonomic cells in the turtle spinal cord. Neurosci Lett 14:141-146.

Kusuma A, ten Donkelaar HJ (1980a) Dorsal root projections in various types of reptiles. Brain Behav Evol 17:291-309.

Kusuma A, ten Donkelaar HJ (1980b) Propriospinal fibers interconnecting the spinal enlargements in some quadrupedal reptiles. J Comp Neurol 193:871-891.

Larimer JL (1988) The command hypothesis: a new view using an old example. Trends Neurosci 11:506-510.

Lee C, Rohrer WH, Sparks DL (1988) Population coding of saccadic eye movements by neurons in the superior colliculus. Nature 332 357-360.

Marcus LC (1981) Veterinary biology and medicine of captive amphibians and reptiles. Philadelphia: Lea and Febiger.

Melby EC, Altman NH (1974) Handbook of laboratory animal science, Vol 1. Cleveland: CRC.

Mortin LI, Stcin PSG (1989) Spinal cord scgments containing kcy elements of the central pattern generators for three forms of scratch reflex in the turtle. J Neurosci 9:2285-2296.

Mortin LI, Stein PSG (1990) Cutaneous dermatomes for the initiation of three forms of the scratch reflex in the spinal turtle. J Comp Neurol 295:515-529.

Mortin LI, Keifer J, Stein PSG (1985) Three forms of the scratch reflex in the spinal turtle: movement analyses. J Neurophysiol 53:15011516.

Pratt CA, Jordan LM (1987) Ia inhibitory interneurons and Renshaw cells as contributors to the spinal mechanisms of fictive locomotion. J Neurophysiol 57:56-71.
Roberts A (1989) The neurons that control axial movements in a frog embryo. Am Zool 29:53-63.

Robertson GA, Stein PSG (1988) Synaptic control of hindlimb motoneurones during three forms of the fictive scratch reflex in the turtle. J Physiol (Lond) 404:101-128.

Robertson GA, Mortin LI, Keifer J, Stein PSG (1985) Three forms of the scratch reflex in the spinal turtle: central generation of motor patterns. J Neurophysiol 53:1517-1534.

Ruigrok TJH (1984) Organization and morphology of motoneurons and primary afferents in the lumbar spinal cord of the turtle Pseudemys scripta elegans. PhD thesis, University of Utrecht.

Schwartz AB, Kettner RE, Georgopoulos AP (1988) Primate motor cortex and free arm movements to visual targets in three-dimensional space. I. Relations between single cell discharge and direction of movement. J Neurosci 8:2913-2927.

Shcfchyk S, McCrca D, Kriellaars D, Fortier P, Jordan L (1990) Activity of interneurons within the L4 spinal segment of the cat during brainstem-evoked fictive locomotion. Exp Brain Res 80:290-295.

Sillar KT (1989) Synaptic modulation of cutaneous pathways in the vertebrate spinal cord. Semin Neurosci 1:45-54.

Sillar KT, Roberts A (1992) Phase-dependent modulation of a cutaneous sensory pathway by glycinergic inhibition from the locomotor rhythm generator in Xenopus embryos. Eur J Neurosci 4:1022-1034.

Sparks DL, Holland R, Guthrie BL (1976) Size and distribution of movement fields in the monkey superior colliculus. Brain Res 113: 21-34.

Stein PSG (1989) Spinal cord circuits for motor pattern selection in the turtle. Ann NY Acad Sci 563:1-10.

Stein PSG, Grossman ML (1980) Central program for scratch reflex in turtle. J Comp Physiol 140:287-294.

Wiersma CAG, Ikeda K (1964) Interneurons commanding swimmeret movements in the crayfish, Procambarus clarki (Girard). Comp Biochem Physiol 12:509-525.

Wine JJ, Krasne FB (1972) The organization of escape behavior in the crayfish. J Exp Biol 56:1-18.

Woolf CJ, King AE (1989) Subthreshold components of the cutaneous mechanoreceptive fields of dorsal horn neurons in the rat lumbar spinal cord. J Neurophysiol 62:907-916. 